\title{
Behavioral, neuromorphological, and neurobiochemical effects induced by omega-3 fatty acids following basal forebrain cholinergic depletion in aged mice
}

Debora Cutuli ${ }^{1,2^{*}}$ (D) Eugenia Landolfo ${ }^{1,2}$, Annalisa Nobili ${ }^{1,3}$, Paola De Bartolo ${ }^{1,4}$, Stefano Sacchetti ${ }^{2}$, Doriana Chirico ${ }^{5}$, Federica Marini ${ }^{6,7}$, Luisa Pieroni ${ }^{1}$, Maurizio Ronci ${ }^{8}$, Marcello D'Amelio ${ }^{1,3}$, Francesca Romana D'Amato ${ }^{5}$,

Stefano Farioli-Vecchioli ${ }^{5+}$ and Laura Petrosini ${ }^{1+}$

\begin{abstract}
Background: In recent years, mechanistic, epidemiologic, and interventional studies have indicated beneficial effects of omega-3 polyunsaturated fatty acids (n-3 PUFA) against brain aging and age-related cognitive decline, with the most consistent effects against Alzheimer's disease (AD) confined especially in the early or prodromal stages of the pathology.

In the present study, we investigated the action of n-3 PUFA supplementation on behavioral performances and hippocampal neurogenesis, volume, and astrogliosis in aged mice subjected to a selective depletion of basal forebrain cholinergic neurons. Such a lesion represents a valuable model to mimic one of the most reliable hallmarks of early $\mathrm{AD}$ neuropathology.
\end{abstract}

Methods: Aged mice first underwent mu-p75-saporin immunotoxin intraventricular lesions to obtain a massive cholinergic depletion and then were orally supplemented with n-3 PUFA or olive oil (as isocaloric control) for 8 weeks. Four weeks after the beginning of the dietary supplementation, anxiety levels as well as mnesic, social, and depressive-like behaviors were evaluated. Subsequently, hippocampal morphological and biochemical analyses and n-3 PUFA brain quantification were carried out.

Results: The n-3 PUFA treatment regulated the anxiety alterations and reverted the novelty recognition memory impairment induced by the cholinergic depletion in aged mice. Moreover, n-3 PUFA preserved hippocampal volume, enhanced neurogenesis in the dentate gyrus, and reduced astrogliosis in the hippocampus. Brain levels of n-3 PUFA were positively related to mnesic abilities.

(Continued on next page)

\footnotetext{
* Correspondence: debora.cutuli@uniroma1.it; debora_cutuli@yahoo.it

Authors Eugenia Landolfo and Stefano Sacchetti are part of the PhD

Program in Behavioral Neuroscience.

${ }^{\dagger}$ Stefano Farioli-Vecchioli and Laura Petrosini contributed equally to this work.

'IRCCS Fondazione Santa Lucia, Rome, Italy

2University of Rome "Sapienza", Rome, Italy

Full list of author information is available at the end of the article
}

C The Author(s). 2020 Open Access This article is licensed under a Creative Commons Attribution 4.0 International License, which permits use, sharing, adaptation, distribution and reproduction in any medium or format, as long as you give appropriate credit to the original author(s) and the source, provide a link to the Creative Commons licence, and indicate if changes were made. The images or other third party material in this article are included in the article's Creative Commons licence, unless indicated otherwise in a credit line to the material. If material is not included in the article's Creative Commons licence and your intended use is not permitted by statutory regulation or exceeds the permitted use, you will need to obtain permission directly from the copyright holder. To view a copy of this licence, visit http://creativecommons.org/licenses/by/4.0/. The Creative Commons Public Domain Dedication waiver (http://creativecommons.org/publicdomain/zero/1.0/) applies to the data made available in this article, unless otherwise stated in a credit line to the data. 
(Continued from previous page)

Conclusions: The demonstration that n-3 PUFA are able to counteract behavioral deficits and hippocampal neurodegeneration in cholinergically depleted aged mice promotes their use as a low-cost, safe nutraceutical tool to improve life quality at old age, even in the presence of first stages of AD.

Keywords: Aging, Cholinergic system, Omega-3 fatty acids, Memory deficits, Diet, Alzheimer's disease

\section{Introduction}

Omega-3 polyunsaturated fatty acids (n-3 PUFA) are essential dietary nutrients that constitute the major components of neuronal membranes and are key modulators of many neural functions throughout life [1-4]. Their daily intake could be mainly from plant-derived alphalinolenic acid (ALA) and from fish- and marine-derived eicosapentaenoic acid (EPA) and docosahexaenoic acid (DHA), and their supplements [5, 6]. Unfortunately, nutritional research indicates that the "Western pattern diet" does not provide the brain with an optimal supply of n-3 PUFA, and aging per se is associated to a decrease in cerebral n-3 PUFA due to a reduced absorption, an inefficient biological ability to make long-chain n-3 PUFA (as EPA, DHA, and docosapentaenoic acid, DPA) from shorter chained fatty acids (as ALA), and a diminished n-3 PUFA capacity to cross the blood-brain barrier [7-9]. When diet does not provide enough n-3 PUFA, vulnerability to several diseases can increase [6]. Therefore, especially during aging, dietary interventions aimed to better balance these fatty acids could be important.

The ever-increasing number of elderly people translates into increasing demands for social-health and care services, particularly with respect to age-related neurodegenerative diseases, such as Alzheimer's disease (AD). $\mathrm{AD}$ is the most common progressive dementia in people over the age of 65 years [10, 11]. Major symptoms of AD are memory loss, speech and language impairment, abstract reasoning decline, and mood changes [12, 13]. The main neuropathological hallmarks of $\mathrm{AD}$ include extracellular deposits of amyloid- $\beta$ (A $\beta)$, intracellular neurofibrillary tangles of tau protein, glial responses, and neuronal and synaptic loss in the limbic system, neocortical regions, and basal forebrain areas [12, 14, 15]. In $\mathrm{AD}$ patients, hippocampal-dependent functions are severely compromised and in vivo and post-mortem studies have reported remarkable shrinkage of the hippocampus [16-18]. Moreover, alterations in adult hippocampal neurogenesis have been reported at early AD stages, before the generalized presence of senile plaques or neurofibrillary tangles in the dentate gyrus (DG) [19-21].

The etiology of AD is still unknown, and no effective therapy has been yet identified to defeat the disease. Currently, there are only symptomatic treatments to attenuate AD-related cognitive deterioration which have no effects on $A D$ progression [22-24], and vaccines are not yet available [25]. On this basis, there is substantial interest in identifying lifestyle factors, such as diet, capable of preventing or at least delaying cognitive decline at old age [26].

Current animal and human evidence, although somewhat inconsistent, indicates that n-3 PUFA supplementation may be beneficial against age-related dysfunctions. Specifically, in animal studies, learning and memory abilities as well as neurogenic and synaptogenic functions can be ameliorated by $n-3$ PUFA treatment during aging and in AD preclinical models [2, 3, 20, 27-30]. With regard to human studies, some observational and epidemiological studies and recent meta-analyses reported that n-3 PUFA intake is associated with improved cognition in older adults and in patients with mild cognitive impairment (MCI) [31-33], and with a lower risk of dementia and $\mathrm{AD}$ [27, 34-37]. Anyway, interventional studies showed contradictory results on the relationship between n-3 PUFA administration and cognitive performances during aging, with some studies succeeding [38-43] and other studies failing [38, 43-47] in revealing significant beneficial cognitive effects in older adults and patients with MCI and AD. Notably, comprehensive systematic reviews of the literature on randomized controlled trials reveal that there is no consistent evidence to support the effectiveness of $n-3$ PUFA supplementation in improving cognitive functions in $\mathrm{AD}$ patients, especially in case of advanced $\mathrm{AD}[36,48-50]$. When present, cognitive improvements associated with n-3 PUFA supplementation have been mostly demonstrated in patients with very mild AD [48, 51, 52].

The intracerebroventricular (i.c.v.) injection of the mup75-saporin (saporin) immunotoxin is a valid animal model to partially mimic early AD pathology in mice, since the loss of integrity of the basal forebrain cholinergic system is one of the most reliable hallmarks of AD pathology [53]. Namely, the saporin immunotoxin provokes a selective and permanent removal of basal forebrain cholinergic inputs to the hippocampus, the entire cortical mantle, the amygdala, and the olfactory bulb [54-56].

Furthermore, animal studies offer better possibilities for controlled n-3 PUFA supplementation than interventional studies in humans allowing on one hand to better manage confounding factors, such as disease stage, age, cooking processes, other dietary components, socio- 
economic status, genetic background, healthy habits (e.g., exercise, not smoking, good sleep, social support, use of vitamin supplement, etc.), and on the other hand to better analyze the neural mechanisms underlying the eventual cognitive and behavioral improvements observed in the animal models.

Thus, in the present study, we used saporin immunotoxin i.c.v. injections as experimental model of $\mathrm{AD}$ first stages, which have been demonstrated to be the most crucial phase to observe n-3 PUFA beneficial effects against AD pathology in humans [51]. We then investigated the impact of an 8-week oral post-lesional administration of a mixture of EPA, DHA, and DPA on the cognitive and behavioral performances and hippocampal degeneration induced by immunotoxic forebrain cholinergic lesions during aging. To this aim, we compared emotional, mnesic, and social performances as well as hippocampal morphological and biochemical correlates of cholinergically depleted or sham-lesioned aged mice supplemented with n-3 PUFA with those which received olive oil (used as isocaloric control). In particular, after the behavioral evaluation, the neurodegeneration of hippocampal networks was analyzed by measuring neurogenesis levels in the DG and volumes and astrogliosis in the hippocampus, which is one of the main target areas of the lesioned cholinergic projections from medial septum/diagonal band. A quantification of n-3 PUFA brain levels was also performed.

\section{Materials and methods}

\section{Animals}

C57BL/6 male mice $(n=57)$ purchased from Envigo (S. Pietro al Natisone, Italy) were used. At their arrival, the animals were $8-9$ months old and they were all exbreeders. The animals were group-housed (3-4 mice/ cage) with controlled temperature $\left(22-23^{\circ} \mathrm{C}\right)$ and humidity $(60 \pm 5 \%)$, under a 12:12 h light/dark cycle (lights on at 07:00 a.m.), with food and water freely available throughout the study.

Animals were randomly assigned to the following experimental groups:

- Sham-lesioned aged mice supplemented with olive oil (sham oil, $n=14$ );

- Sham-lesioned aged mice supplemented with n-3 PUFA (sham n-3 PUFA, $n=16$ );

- mu-p75-saporin-lesioned aged mice supplemented with olive oil (sap oil, $n=12$ );

- mu-p75-saporin-lesioned aged mice supplemented with n-3 PUFA (sap n-3 PUFA, $n=15$ ).

All efforts were made to minimize animal suffering and reduce the number of mice used, in accordance with the European Union Directive of September 22, 2010
(2010/63/EU). All experiments were approved by the Italian Ministry of Health (Legislative Decree No 682/ 2016).

\section{Experimental procedures}

To evaluate the potential therapeutic action of $n-3$ PUFA in the presence of a cholinergic depletion during aging, when $\approx 21$ months old, mice were intraventricularly injected with the mu-p75-saporin immunotoxin (or saline) to induce (or not) a selective degeneration of basal forebrain cholinergic neurons. After 2 weeks, the animals began the supplementation by gavage with $n-3$ PUFA (or olive oil) lasting for 8 weeks. Four weeks after the gavage beginning, mice underwent the behavioral evaluation. At the end of gavage period, mice were sacrificed, and brains were collected for morphological, biochemical, and lipid analyses (Fig. 1).

\section{Surgery}

The mu-p75-saporin is used to selectively deplete the central cholinergic system in mice. It is made by conjugating the low affinity p75 neurotrophin receptor (p75NTR) antibody to saporin, a ribosome inactivating protein. When the conjugate is internalized, mu-p75saporin breaks away from the targeting agent and inactivates the ribosomes causing protein synthesis inhibition and, ultimately, cell death. In this way, the immunotoxin is able to eliminate cells expressing p75NTR in mouse as the cholinergic basal forebrain neurons, while sparing neighboring neurons that express glutamic acid decarboxylase, calbindin, and parvalbumin. The resulting permanent and selective saporin-dependent massive loss of cortical and hippocampal cholinergic afferents mimics neuropathological features and cognitive symptoms associated with MCI and early AD.

The mice assigned to the immunotoxic lesioned groups were intraventricularly injected with the mu-p75saporin (Targeting Systems, San Diego, CA), while the sham-lesioned groups were intraventricularly injected with $0.9 \%$ saline.

Mice were anesthetized with a mixture of tiletamine/ zolazepam (50 mg/kg Zoletil 100 i.p., Virbac s.r.l., Milan, Italy) and xylazine $(10 \mathrm{mg} / \mathrm{kg}$ Rompun i.p., Bayer s.p.a., Milan, Italy). In the animals that had to be immunotoxic lesioned $(n=27)$, the mu-p75-saporin was injected through a 10- $\mu$ l Hamilton syringe in each lateral ventricle (total dosage: $0.6 \mu \mathrm{g} /$ mouse $[54,57]$, coordinates: antero-posterior $(\mathrm{AP})=-0.6 \mathrm{~mm}$ (from the bregma); medio-lateral $(\mathrm{ML})= \pm 1 \mathrm{~mm}$ (from the midline); dorsoventral $(D V)=-2.2 \mathrm{~mm}$ (from the dura) [58]. The immunotoxin $(0.3 \mu \mathrm{l}$ per side) was injected at a rate of $0.1 \mu \mathrm{l} / \mathrm{min}$. At the end of injection, the needle was left in situ for 4 min to allow the diffusion. 


\section{Experimental procedures}

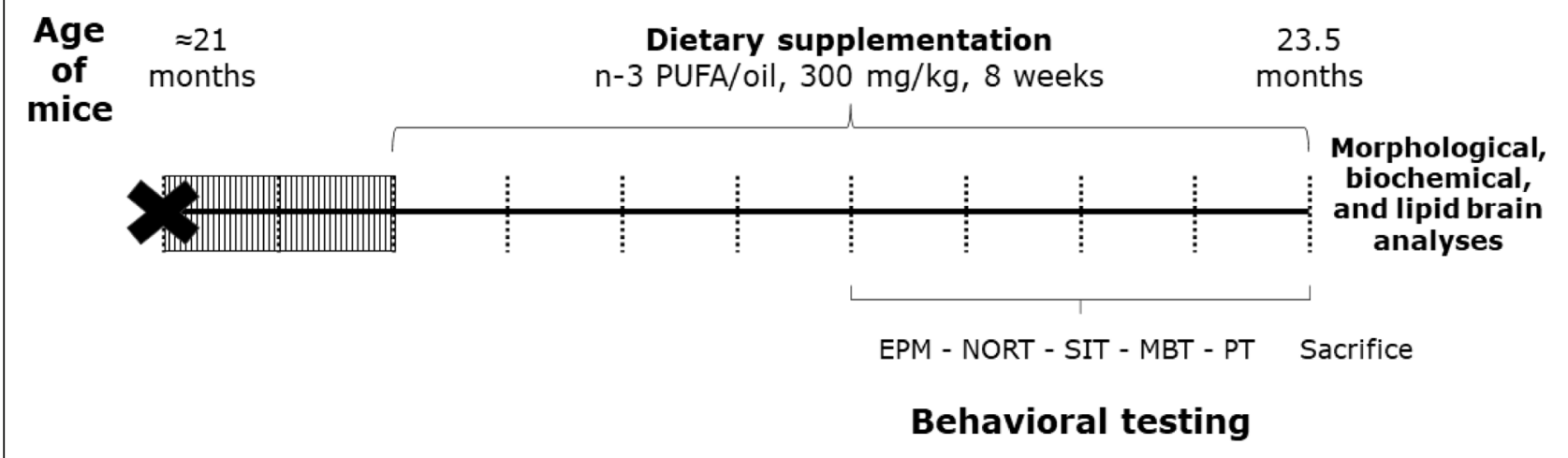

\section{Cholinergic neuronal degeneration}

Fig. 1 Experimental procedures. At $\approx 21$ months of age, mice were subjected to i.c.v. injections of mu-p75-saporin or saline (sham lesion) to selectively deplete the forebrain cholinergic system. Two weeks after lesion, an 8-week oral supplementation (by gavage) with n-3 PUFA or olive oil began. After the first 4 weeks of dietary supplementation, the animals were behaviorally evaluated by means of a testing battery (elevated plus maze, EPM; novel object recognition task, NORT; social interactions test, SIT; marble burying test, MBT; Porsolt test, PT) lasting 4 weeks. At the end of testing, the mice were sacrificed, and brains collected for morphological, biochemical, and lipid analyses

In the remaining mice used as sham-lesioned controls $(n=30), 0.9 \%$ saline $(0.3 \mu$ l per side) was injected into each lateral ventricle with the same injection procedure.

\section{Dietary manipulations}

Two weeks after lesioning (time required to allow the immunotoxin to permanently deplete cholinergic neurons [54]), mice were supplemented by gavage for 8 weeks with a mixture of n-3 PUFA (containing 52\% EPA, 39.2\% DHA and 6\% DPA; Meaquor 900, UGA Nutraceuticals, Italy) or olive oil (used as isocaloric control, containing $14.6 \%$ saturated fatty acids, $68.3 \%$ monounsaturated fatty acids and $8.7 \%$ PUFA of which $0.6 \% \mathrm{n}-3$ PUFA, i.e., ALA; De Cecco, Italy) at a $300 \mathrm{mg} /$ $\mathrm{kg}$ dosage.

All animals were fed ad libitum with standard food pellets (Mucedola 4RF21 standard diet; Mucedola, Italy).

\section{Behavioral testing}

Four weeks after n-3 PUFA (or olive oil) supplementation beginning (time expected to incorporate n-3 PUFA in the neuronal membranes $[59,60]$ and to habituate to gavage procedure), the animals underwent the following behavioral battery of validated tests tapping distinct cognitive and emotional functions: novel object recognition task (NORT) to evaluate recognition memory, elevated plus maze (EPM) and marble burying test (MBT) to measure anxious behaviors, social interactions test (SIT) to assess social behaviors, and Porsolt test (PT) to analyze depressive-like behaviors (Fig. 1). Half of each experimental group was exposed to NORT or MBT first alternatively, to control the effect of novelty-i.e., objects or marbles, while the other tests were administered in the same order as in Fig. 1.

All tests were performed between 10:00 a.m. and 06: 00 p.m. All animals were subjected to handling habituation prior to the behavioral testing. Animals were tested in a pseudo-random order during each different task.

\section{Elevated plus maze (EPM)}

The elevated plus maze (EPM) is a validated test to measure anxiety levels in rodents based on their natural proclivity toward dark, enclosed spaces and aversion for heights/open spaces [61-64]. In aging mice, anxiety is expected to increase [65]. Furthermore, cholinergic manipulations are known to modify anxiety levels [66, 67]. The maze consisted of a wooden cross-shaped structure elevated $60 \mathrm{~cm}$ above the floor, with a central platform $(5 \times 5 \mathrm{~cm})$ and four $30 \times 5 \mathrm{~cm}$ arms. The two oppositely positioned closed arms were enclosed by walls $20 \mathrm{~cm}$ high, while the two oppositely positioned open arms had no walls.

During a 5-min trial, the mouse was placed in the central platform and allowed to freely explore the apparatus. The maze was cleaned with a solution of $10 \%$ ethanol after each trial to remove olfactory clues. Trials were 
recorded by a ceiling-mounted camera and analyzed by a video analyzer (EthoVision XT, Noldus, The Netherlands). The following parameters were measured: total entries and total time spent in the open and closed arms; number of defecations.

\section{Novel object recognition task (NORT)}

The novel object recognition task (NORT) is a validated test to measure recognition memory in rodents that exploits their natural tendency to explore novel items [68] and is strictly dependent on hippocampal integrity $[69,70]$.

The apparatus consisted of a chamber made of transparent Plexiglas $(56 \times 42 \times 21 \mathrm{~cm})$. The test was composed of three 5-min trials: habituation, training, and test trial $[71,72]$. During habituation, mice were allowed to explore the empty chamber. Afterwards, mice were put in their home cages for $3 \mathrm{~min}$. Then, during training trial, they were exposed to the now-familiar chamber containing two identical objects (objects $\mathrm{A}$ and $\mathrm{B}$; two white Plexiglas $6.5-\mathrm{cm}$ diameter spheres fixed to a $4 \mathrm{~mm}$ thick transparent squared base). One hour later, mice were once again exposed to the familiar chamber containing one familiar object (object A) and a novel object (a white cube of $5.5-\mathrm{cm}$ side fixed to a $4 \mathrm{~mm}$ thick transparent squared base) to test long-term recognition memory (test trial). Contact time was considered to have occurred when the animal explored the object for at least $1 \mathrm{~s}$. To balance for side bias, we randomly put each animal into the testing chamber from the opposite long sides of the apparatus (with the snout against the wall), so that if for one animal the object $\mathrm{A}$ was on the right and the novel object (and previously the object B) on the left, conversely for another animal inserted in the apparatus from the opposite side the object $\mathrm{A}$ was on the left and the novel object (and previously the object $\mathrm{B}$ ) on the right.

The arena was cleaned with a solution of $10 \%$ ethanol after each trial to minimize olfactory signals.

A video camera connected to a monitor and to the image analyzer (EthoVision XT, Noldus, The Netherlands) was placed on top of the apparatus. To assess novel object recognition (novelty) memory the time spent exploring each object during the test trial was recorded and a discrimination index was calculated:

contact time with the novel object (Tno) - contact time with the familiar one (Tfo) total contact time with objects $($ Tno + Tfo $)$

Further explorative parameters were the distance traveled in the arena (as index of horizontal exploration) and the number of rearings and wall-rearings (as index of vertical exploration). As emotional parameters, we considered grooming time and number of defecations.

\section{Marble burying test (MBT)}

The marble burying test (MBT) is a validated test to measure the neophobic, anxious, and repetitive behaviors of mice [73, 74]. We used this test to evaluate the eventual effects on anxiety following the cholinergic lesion in aged mice [67]. The apparatus consisted of a rectangular cage made of transparent Plexiglas $(40 \times$ $24 \times 17 \mathrm{~cm}$ ) filled with sawdust $5 \mathrm{~cm}$ deep, without food and water. Nine glass marbles $(1.5 \mathrm{~cm}$ in diameter) were equidistantly spaced on the flattened surface of the bedding in a $3 \times 3$ grid. During the test, each mouse was allowed to explore the apparatus for $30 \mathrm{~min}$. At the end of the test, the number of successfully buried marbles was counted. A marble was considered buried when at least $2 / 3$ of its size was covered with sawdust $[74,75]$.

\section{Social interactions test (SIT)}

The social interactions test (SIT) is used to investigate social behaviors, which are known to decrease with age in rodents $[65,76]$. Moreover, a selective cholinergic depletion of neocortex is reported to cause a significant decrease in the duration of active social interaction with an unfamiliar male in adult rats [77].

We isolated all males for $24 \mathrm{~h}$ in clean cages. The experimental trial started when an unfamiliar female mouse (2-month old and in the oestrus phase) was placed into the male's cage for $10 \mathrm{~min}$. A video camera was placed in front of the apparatus and videos were analyzed with the Observer software (Noldus, The Netherlands). Non-social, social, and sexual males' behaviors were evaluated [78]. Non-social behaviors included exploration, rearing, wall-rearing, sniffing, digging, and self-grooming. Social behaviors included social investigation (following, sniffing head, body, and ano-genital region of the partner) and allogrooming (grooming the partner). Sexual behavior included mounts and pelvic thrusts.

\section{Porsolt test (PT)}

The Porsolt test (PT) is a validated test evaluating depressive-like behaviors and coping strategies $[79,80]$. In the present study, we assessed depressive-like behavior with PT since depression is frequently identified in elderly individuals, also at subthreshold levels and with a high prevalence in the community-dwelling elderly individuals [81, 82].

The apparatus consisted of a glass cylinder (diameter $18 \mathrm{~cm}$, height $40 \mathrm{~cm}$ ) containing $20 \mathrm{~cm}$ water at $28 \pm$ $2{ }^{\circ} \mathrm{C}$. The mice were submitted to a 5 -min pre-test session. Twenty-four hours later, mice were tested for the second time in the same apparatus for $5 \mathrm{~min}$ (test session) [83]. At the end of each session, mice were removed from the cylinder, placed under a heat source for a while and allowed to dry in small cages. Then, the 
mice were brought back to their home cages. Animals' behavior was recorded by using a frontally mounted video camera. Later, an observer blind to the specimen's group manually scored the videos (EthoVision XT, Noldus, The Netherlands).

The total immobility time was recorded as index of behavioral despair. Immobility was defined as the total absence of any movements except for those necessary to float and for respiration.

\section{Morphological analyses \\ Bromodeoxyuridine (BrdU) treatment and immunocytochemistry}

In aging, the DG of the hippocampus exhibits a severe decrease of progenitor proliferation, resulting in progressive decline of adult neurogenesis [84, 85]. The neuroinflammatory response after injury is characterized by a striking increase of glial fibrillary acidic protein positive $\left(\mathrm{GFAP}^{+}\right)$astrocytic population, a process named astrocytosis $[86,87]$. In the present study, we assessed n-3 PUFA effects on the proliferation and differentiation of newborn neurons as well as on the number of $\mathrm{GFAP}^{+}$ cells in the DG of the four experimental groups.

Five mice per group received daily i.p. injections of $50 \mathrm{mg} / \mathrm{kg}$ of $\mathrm{BrdU}$ dissolved in saline $(0.9 \% \mathrm{NaCl}$ adjusted to $\mathrm{pH} 7.2$ with $\mathrm{NaOH}$ ) for 5 days. One day after the final injection, the animals were sacrificed and transcardially perfused, under deep anesthesia with a mixture of tiletamine/zolazepam $(500 \mathrm{mg} / \mathrm{kg}$ Zoletil 100 i.p., Virbac s.r.l., Milan, Italy) and xylazine (100 mg/kg Rompun i.p., Bayer s.p.a., Milan, Italy) with $4 \%$ paraformaldehyde (PFA) in $0.1 \mathrm{M}$ phosphate buffer (PBS). The brains were removed and kept overnight in 4\% PFA. Afterwards, brains were equilibrated in $30 \%$ sucrose and cryopreserved at $-80^{\circ} \mathrm{C}$.

Brains embedded in Tissue-Tek OCT (Sakura, USA) were cut by cryostat at $-25^{\circ} \mathrm{C}$ in $40 \mu \mathrm{m}$ coronal serial free-floating sections. To detect BrdU, DNA was denatured with $2 \mathrm{~N} \mathrm{HCl}$ for $40 \mathrm{~min}$ at $37{ }^{\circ} \mathrm{C}$ to facilitate antibody access, followed by $0.1 \mathrm{M}$ borate buffer ( $\mathrm{pH}$ 8.5) for $20 \mathrm{~min}$. Sections were incubated overnight at $4{ }^{\circ} \mathrm{C}$ with a primary antibody rat anti-BrdU (AbD Serotec Cat\# MCA2060) diluted 1:300 in Tris-buffered saline containing $0.1 \%$ Triton, $0.1 \%$ Tween 20 , and $3 \%$ normal donkey serum (blocking solution).

For immunofluorescence analysis, the sections were then stained for multiple labeling by using fluorescent methods. After permeabilization with $0.3 \%$ Triton X-100 in PBS, the sections were incubated with $3 \%$ normal donkey serum in PBS for 16-18 $\mathrm{h}$ with the following primary antibodies: 1:200 goat polyclonal antibodies against doublecortin (DCX) (Santa Cruz Biotechnology, Inc. Cat\# sc-8066), 1:300 goat polyclonal antibodies against sex-determining region Y-box 2 (SOX2) (Santa Cruz
Biotechnology, Inc. Cat\# 17320), and 1:500 mouse monoclonal antibodies against GFAP (SIGMA Cat\# G6171). The secondary antibodies used to visualize the antigen were as follows: 1:200 donkey anti-rat Cy3conjugated (Jackson ImmunoResearch; BrdU), 1:200 donkey anti-goat Cy3-conjugated (Jackson ImmunoResearch DCX, SOX2), and 1:200 donkey anti-mouse Cy2conjugated (Jackson ImmunoResearch GFAP).

Images of the immunostained sections were obtained by laser scanning confocal microscopy using a TCS SP5 microscope (Leica Microsystem, Germany).

Analyses were performed in sequential scanning mode to rule out cross-bleeding between channels.

\section{Quantification of cell number}

To estimate the number of positive cells in the DG, we combined confocal z-stack imaging and optical dissector analysis as established by others [88, 89].

Slices were collected using systematic random sampling. The brain was coronally sliced in rostro-caudal direction, thus including the dorsal hippocampal region (approximately from bregma -1.06 to -2.54 [90]). Approximately total of 40 coronal sections with $40 \mu \mathrm{m}$ of thickness were obtained from each brain; about 1-in-6 series of sections (each slice thus spaced $240 \mu \mathrm{m}$ apart from the next) were analyzed by confocal microscopy and used to count the number of cells expressing the different markers throughout the rostro-caudal extent of the dorsal hippocampus. Quantification of BrdU, SOX2, DCX, and $\mathrm{GFAP}^{+}$cells in the dorsal DG has been obtained in every sixth coronal section (6 sections per brain) spanning the dorsal region of hippocampus. One optical section stack was obtained from three different sub-regions of the DG (the crest, the suprapyramidal, and the infrapyramidal blade) using a CLSM (TCS-SP2; Leica Microsystem) equipped with an oil immersion objective lens ( $\times 63$, NA 1.32). To allow an efficient optical dissector analysis, we optimized the sampling conditions as follows: pixel size $=0.30 \times 0.30 \mu \mathrm{m}$, slice interval $=$ $1.5 \mu \mathrm{m}$, slice number $=20$, and unbiased counting frame size $=225 \times 200 \mathrm{~mm}$. These optical sections were projected, and a montage was composed of the projected sections with NIH ImageJ. Quantitative analysis of hippocampal cell populations was performed by means of design-based (assumption-free, unbiased) stereological method, the optical dissector [91]. The unbiased counting frame [92] was superimposed by using the Blend Images Plugin of ImageJ. With the lost cap bias taken into consideration, the start and end points of the optical dissector height were set at approximately $2 \mathrm{~mm}$ inside the cut surface of mounted tissue. Then, the optical section at the start point was used as a look-up section, and the remaining optical sections were used as reference sections. According to the optical dissector principle, all 
cells cut through the lookup section or touching an exclusion line were disregarded, and they were marked in one color using the Cell Counter plugin of ImageJ (NIMH). The cells cut exclusively through the reference sections were counted and marked in a different color, as long as they were touching an inclusion line or were completely within the frame.

The total number of markers within the single section of DG was obtained as:

$$
\mathrm{N}=\sum \mathrm{Q}^{-} /(\mathrm{h} / \mathrm{SV})
$$

where " $\Sigma \mathrm{Q}^{-}$" was the number of dissector-counted cell, " $h$ " was the height of the optical dissector, and "SV" was the volumetric shrinkage factor (0.65).

The estimation of the total DG cell numbers was obtained by multiplying the average number of positive cells per section by the total number of $40 \mu \mathrm{m}$ sections [93-95].

\section{Volumetric measurement}

Rostro-caudal sections of the dorsal horn of hippocampus (approximately from bregma -1.06 to -2.54 [58]) of each animal were mounted onto glass slide and stained with 4',6-diamidino-2-phenylindole (DAPI) for $1 \mathrm{~min}$. Stained sections were viewed at low magnification by using Olympus BX53 digital photomicroscope. Digital images were then captured electronically and displayed on a computer screen. The volume of the total hippocampus and its subregions were unbiasedly estimated by means of point counting methods, using the Cavalieri's principle $[96,97]$. Briefly, a $200-\mu \mathrm{m}^{2}$ point counting grid was superimposed on the images. The points hitting on the total hippocampus and its subfields (DG, CA1+CA3) were separately counted. The total volume of the hippocampus and its subfields was determined by applying the following formula:

$$
\text { Volume }=\sum \mathrm{Pxd} \times \mathrm{t} \times \mathrm{a} / \mathrm{p}
$$

where " $\Sigma \mathrm{P}$ " represented the number of points hitting the region analyzed, " $d$ " was equal to the distance from one section to the next $(d=0.24 \mathrm{~mm})$, " $t$ " was the mean section thickness $(t=0.04 \mathrm{~mm})$, and "a/p" was equal to the area associated with one point in the grid.

\section{Biochemical analyses \\ Total protein extraction}

Hippocampi were isolated from the entire brain and tissues were homogenized in lysis buffer containing (in $\mathrm{mM}$ ) 320 sucrose, $50 \mathrm{NaCl}, 50$ Tris- $\mathrm{HCl}$ pH 7.5, $1 \%$ Triton X100,1 sodium orthovanadate, $5 \beta$-glycerophosphate, 5 $\mathrm{NaF}$, and protease inhibitor cocktail. Homogenates were incubated on ice $(30 \mathrm{~min})$ and centrifuged at $15,000 \mathrm{~g}$ at $4{ }^{\circ} \mathrm{C}(10 \mathrm{~min})$ [98]. The total protein content of the supernatant was determined by the Bradford method.

\section{Immunoblotting analysis}

Proteins were applied to SDS-PAGE and electroblotted on a polyvinylidene difluoride membrane. Immunoblotting analysis was performed using a chemiluminescence detection kit. The relative levels of immunoreactivity were determined by densitometry using the Image) software.

The primary antibodies were as follows: vesicular acetylcholine transporter (VAChT) (1:500, Synaptic Systems, \#139103), GFAP (1:1000, Dako, \#Z0334), and Actin (1:10000, Millipore, \#MABT825). The secondary antibodies were as follows: goat anti-mouse IgG (1:3000; Bio-Rad, \# 1706516) and goat anti-rabbit IgG (1:3000; Bio-Rad, \# 1706515).

Membranes were stripped using Re-Blot Plus Strong Solution (Millipore) for $15 \mathrm{~min}$ at room temperature.

\section{Lipid analysis \\ Analysis of $n-3$ PUFA by gas chromatography/mass spectrometry (GC/MS)}

Fatty acids were extracted using the method reported by Folch [99] with slight modifications. Briefly, brains were homogenized in $\mathrm{CHCl} 3 / \mathrm{MeOH}(2: 1 \mathrm{v} / \mathrm{v})$ to a final dilution of 20 -fold of the original sample volume, assuming that the tissue has the same specific gravity of water. Five hundred nanograms per microliter of internal standard mixture composed by pentadecanoic acid, nonadecanoic acid, and eneicosanoic acid was added in all samples. The resulting organic phase was evaporated to dryness in a speed-vac at room temperature and then derivatized by using $25 \mu \mathrm{L} 1 \%$ pentafluorobenzyl bromide in acetonitrile and $25 \mu \mathrm{L} 1 \%$ diisopropylethylamine in acetonitrile and incubated for $20 \mathrm{~min}$ at room temperature [100].

Derivatized samples were dried down under vacuum by using speed vac and then transferred in the injection vials dissolved by $50 \mu \mathrm{L}$ iso-octane.

GC/MS analyses were performed using Trace GC 1310 (Thermo Scientific, USA) equipped with $30 \mathrm{~m} \times$ $0.25 \mathrm{~mm}$ fused silica capillary column SLB TM-5 MS (Supelco) and connected to ISQ Mass Spectrometer (Thermo Scientific, USA). Two microliters of each sample was injected in split mode (1:25), the injection temperature was set at $250{ }^{\circ} \mathrm{C}$; the carrier gas was Helium (ultra-high purity) and the flow rate was maintained constant at $1 \mathrm{~mL} / \mathrm{min}$. The initial oven temperature was $150^{\circ} \mathrm{C}$, rising $10^{\circ} \mathrm{C} / \mathrm{min}$ to $270^{\circ} \mathrm{C}$, and then increased by $40^{\circ} \mathrm{C} / \mathrm{min}$ up to $310^{\circ} \mathrm{C}$, held for $1 \mathrm{~min}$. Both mass transfer line and the ion source were kept constant at $280^{\circ} \mathrm{C}$. MS experiments were led by negative chemical ionization mode (NCI), using Methane (ultrahigh purity) as reagent gas with a constant flow of $0.5 \mathrm{~mL} / \mathrm{min}$ and the quadrupole temperature was set at $150^{\circ} \mathrm{C}$. The analysis was performed by selected ion monitoring (SIM) mode 
low resolution, and the free fatty acids were identified in comparison with commercial standards.

All identification and quantification results were obtained by Xcalibur 3.1 software (Thermo Scientific, USA).

\section{Statistical analyses}

All data were tested for normality (Shapiro-Wilk test). When normally distributed, data were analyzed by using three-way ANOVAs (with lesion and diet as betweenfactors and trial as within-factor) followed by Tukey post-hoc tests. When data were not normally distributed, non-parametric analyses (Kruskal-Wallis ANOVA, Wilcoxon test, Mann-Whitney $U$ test) were used. Morphological data were analyzed by using Student's $T$ test. Values of $p<0.05$ were considered significant (Statistica 12, Statsoft). The sample size was calculated based on a priori power analysis $(1-\beta=0.80, \alpha$ error $=0.05$, two tails; GPower 3.1). For example, to obtain a significant difference between two independent groups in the NORT discrimination index, or in the GFAP levels, or in the hippocampal volume, we should have used samples of at least 10,2 , or 3 animals, respectively. Considering an eventual increased mortality rate due to the age of the animals and the surgery, we used a greater number of animals in each group.

\section{Results}

\section{Behavioral testing}

\section{EPM}

Wilcoxon tests revealed that mice belonging to both sham-lesioned groups significantly entered more frequently (sham oil: $T=6.5, p=0.004$; sham $n-3$ PUFA: $\mathrm{T}=8.5, p=0.002$ ) and spent more time (sham oil: $T=$ 13, $p=0.01$; sham $\mathrm{n}-3$ PUFA: $T=1, p=0.0005)$ in the closed vs. open arms. Conversely, sap oil mice showed no significant differences in total entries (sap oil: $T=28$, $p=0.39)$ and time spent $(T=24, p=0.24)$ in the closed vs. open arms (Fig. 2). Interestingly, the n-3 PUFA treatment was able to restore the expected aversion for the open arms in sap-lesioned mice (frequency: $T=14, p=$ 0.009 ; time: $T=6, p=0.002$ ). Number of defecations (mean and S.E.; sham oil $=1.43 \pm 0.29$; sham $n-3$ PUFA $=$ $1.69 \pm 0.42$; sap oil $=1.42 \pm 0.36$; sap $n-3$ PUFA $=1.13 \pm$ 0.19 ) did not differ among groups (Kruskal-Wallis ANOVA: $H=0.75, p=0.86$ ).

These results indicate that in aged mice treated with olive oil, the mu-p75-saporin lesion induced anxiolytic effects, while in the lesioned aged animals, the n-3 PUFA treatment was able to restore the expected aversion for the open arms.

\section{NORT}

During the training trial, all mice equally explored (for about the $50 \%$ of total object contact time) the two identical objects (Kruskal-Wallis ANOVA, $H=0.03, p=$ 0.85; Suppl. Table 1). During the test trial, sham oil, sham n-3 PUFA, and sap n-3 PUFA mice showed a more evident preference for the novel object (around $64 \%$ of total object contact time) in comparison to sap oil mice (around $41 \%$ of total object contact time; Kruskal-Wallis ANOVA, $H=9.75, \quad p=0.02$; Suppl. Table 1). In fact, Wilcoxon tests revealed a significant difference between the time spent in contact with novel vs. familiar object in all groups (sham oil: $\mathrm{T}=2, p=$ 0.009; sham $\mathrm{n}-3$ PUFA: $\mathrm{T}=10, p=0.004$; sap $\mathrm{n}-3$ PUFA: $\mathrm{T}=10, p=0.01)$, except for sap oil group $(\mathrm{T}=10.5, p=$ 0.29; Fig. 3a). Moreover, Kruskal-Wallis ANOVA on the discrimination index was significant $(H=9.75, p=0.02)$ and Mann-Whitney $U$ comparisons between groups indicated that n-3 PUFA treated lesioned mice recognized object novelty as both sham control groups (sap n-3 PUFA vs. sham oil: $U=48, p=0.17$; sap n-3 PUFA vs. sham n-3 PUFA: $U=65, p=0.13$ ), while sap oil showed the worst recognition memory (sap oil vs. sham oil: $U=$ 16.5, $p=0.01$; sap oil vs. sap n-3 PUFA: $U=28.5, p=$ 0.04) (Fig. 3b).

As for explorative parameters, three-way ANOVAs (lesion $\mathrm{x}$ diet $\mathrm{x}$ trial) revealed significant effects of diet and trial on the horizontal exploration (total distance, lesion effect: $F_{1,44}=0.20, p=0.65$; diet effect: $F_{1,44}=8.92, p=$ 0.005 ; trial effect: $F_{2,88}=43.21, p<0.0000001$; lesion $\mathrm{x}$ diet: $F_{1,44}=0.85, p=0.36$; trial $\mathrm{x}$ lesion: $F_{2,88}=0.44, p=$ 0.64 ; trial $\mathrm{x}$ diet: $F_{2,88}=1.86, p=0.16$; trial $\mathrm{x}$ lesion $\mathrm{x}$ diet: $F_{2,88}=2.07, p=0.13$; Fig. $3 \mathrm{c}$ ) and the vertical exploration (rearings and wall-rearings, lesion effect: $F_{1,44}=1.11, p=$ 0.30 ; diet effect: $F_{1,44}=13.40, p=0.0007$; trial effect: $F_{2,88}=56.30, p<0.0000001$; lesion $\mathrm{x}$ diet: $F_{1,44}=0.33$, $p=0.60$; trial $\mathrm{x}$ lesion: $F_{2,88}=0.99, p=0.37$; trial $\mathrm{x}$ diet: $F_{2,88}=1.93, p=0.15$; trial $\mathrm{x}$ lesion $\mathrm{x}$ diet: $F_{2,88}=0.14, p=$ 0.86; Fig. 3d).

As for emotional parameters, no differences were found among groups. In fact, both Kruskal-Wallis ANOVAs on grooming time (habituation: $H=2.11, p=0.55$; training trial: $H=0.72, p=0.87$; test trial: $H=1.91, p=$ 0.59 ) and number of defecations (habituation: $H=2.87$, $p=0.41$; training trial: $H=1.20, p=0.75$; test trial: $H=$ 7.37, $p=0.06$ ) failed to reveal any significant difference in any trial of the test (Suppl. Table 1).

These findings indicate that n-3 PUFA treatment counteracted the impairments in novelty recognition memory induced by the cholinergic depletion and reduced the horizontal and vertical exploration in both sham and immunotoxic lesioned aged mice.

\section{MBT}

Kruskal-Wallis ANOVA on the total number of marbles buried by the animals belonging to the four experimental groups was significant $(H=14.23, p=0.03)$. Mann- 


\section{Elevated Plus Maze (EPM)}
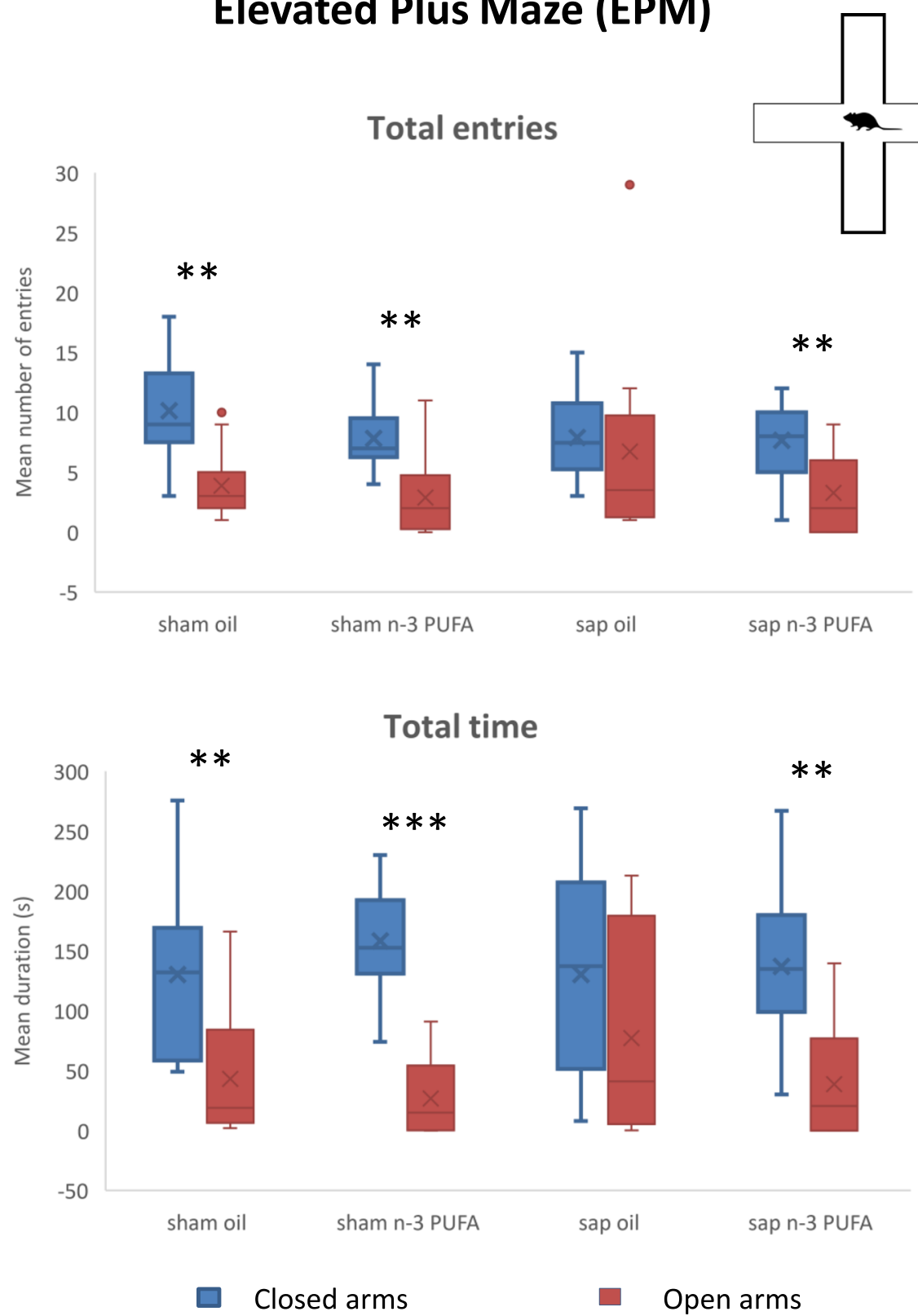

Fig. 2 Elevated plus maze (EPM). Total entries and time spent in the closed and open arms by the four experimental groups (sham oil, $n=14$; sham n-3 PUFA, $n=16$; sap oil, $n=12$; sap $n-3$ PUFA, $n=15)$. ${ }^{* *} p \leq 0.01$, ${ }^{* * *} p<0.001$. In this and the other figures, in box-and-whisker plots, the center line shows the median value, edges are upper and lower quartiles, whiskers show minimum and maximum values, crosses indicate mean values, and any external point is considered an aberrant value

Whitney $U$ comparisons between groups indicated that both sham-lesioned groups buried the same number of marbles $(U=100, p=0.82)$. Sap oil mice buried a lower number of marbles in comparison to sham oil $(U=36.5$, $p=0.01$ ). Sap $\mathrm{n}-3$ PUFA mice did not differ from the remaining experimental groups (vs. sham oil: $U=80.5$, $p=0.28$; vs. sham $\mathrm{n}-3$ PUFA: $U=75.5, p=0.12$; vs. sap oil: $U=70.5, p=0.33$ ) (Fig. 4).
These findings show that in aged mice the mu-p75saporin lesion produced a reduced burying behavior (anxiolytic effect) that the n-3 PUFA treatment only partially rescued.

SIT

Due to technical troubles during SIT data video recording, we were able to analyze the performance of a subset 


\section{Novel Object Recognition Task (NORT)}

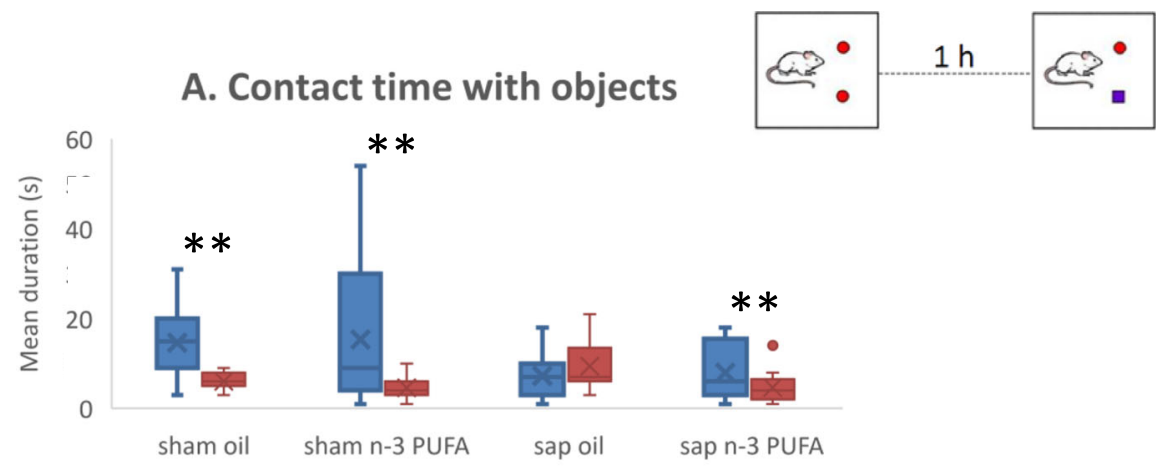

$\square$ Novel object $\square$ Familiar object

B. Discrimination index

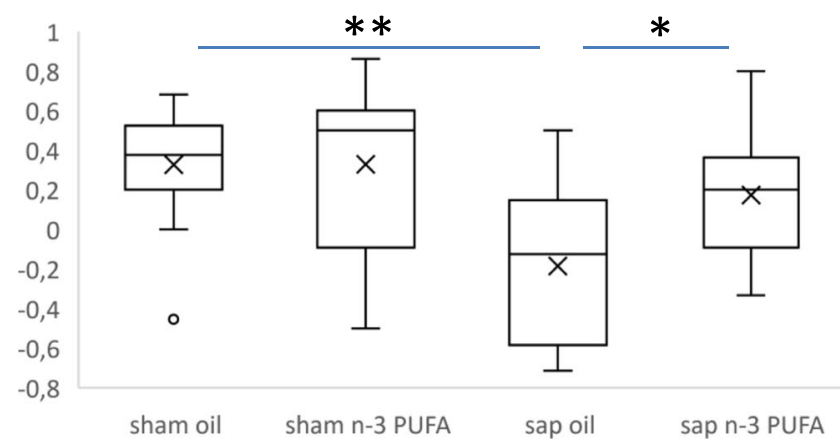

C. Total distance

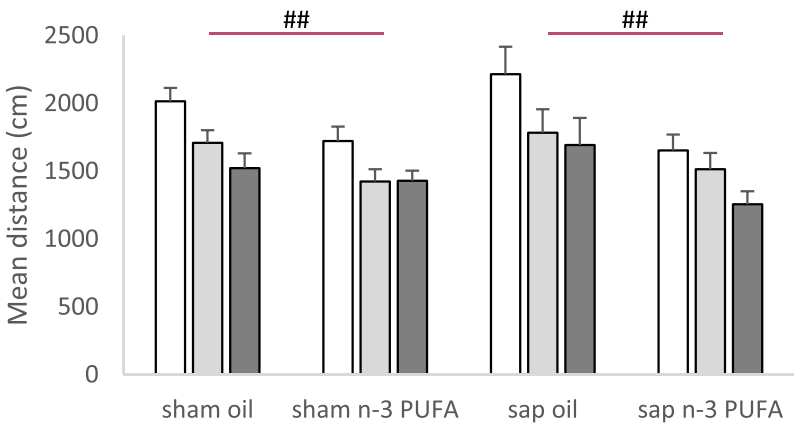

D. Rearings and wall-rearings

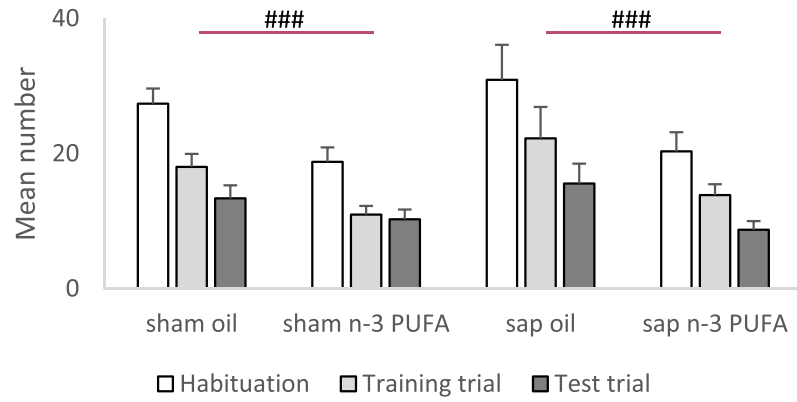

Fig. 3 (See legend on next page.) 
(See figure on previous page.)

Fig. 3 Novel object recognition task (NORT). Contact time with the novel and familiar objects (a), discrimination index (b), total distance (c), and total number of rearings (d) displayed by the four experimental groups (sham oil, $n=11$; sham $n-3$ PUFA, $n=15$; sap oil, $n=9$; sap $n-3$ PUFA, $n=$ 13). Asterisks indicate the level of statistical significance of the comparisons between contact time (s) with the novel vs. familiar object (a) and discrimination index between groups (b): ${ }^{* *} p \leq 0.01,{ }^{* * *} p<0.001$. Hashes indicate the statistical significance of diet effect $(\mathbf{c}, \mathbf{d})$ : \#\#p $<0.01, \# \# \# p<$ 0.001. Post-hoc comparisons between trials in $\mathbf{c}$ (habituation vs. training or test trials, $p<0.001$; training trial vs. test trial, $p<0.05$ ) and $\mathbf{d}$ (habituation vs. training or test trials, $p<0.001$; training trial vs. test trial, $p<0.01$ )

of animals only (sham oil, $n=9$; sham $n-3$ PUFA, $n=9$; sap oil, $n=7$; sap $n-3$ PUFA, $n=10$ ). Sexual behaviors and allogrooming were not observed in any group of mice. No differences in non-social behaviors [sum (mean and S.E.): sham oil $=302.07 \pm 5.51 \mathrm{~s}$; sham $\mathrm{n}-3$ PUFA $=$ $298.80 \pm 8.51 \mathrm{~s} ; \quad$ sap $\quad$ oil $=283.28 \pm 17.64 \mathrm{~s} ; \quad$ sap $n-3$ PUFA $=295.32 \pm 8.07 \mathrm{~s}$ ] and social behaviors [sum (mean and S.E.): sham oil $=29.98 \pm 10 \mathrm{~s}$; sham $\mathrm{n}-3$ PUFA $=$ $23.12 \pm 7.74 \mathrm{~s}$; sap oil $=30.92 \pm 19.36 \mathrm{~s}$; sap $\mathrm{n}-3$ PUFA $=$ $25.68 \pm 6.47 \mathrm{~s}$ ] were found among groups (Table 1 ).

Thus, as expected, the overall social interaction time of the experimental aged subjects with females was low, but not affected by cholinergic depletion or n-3 PUFA treatment.

PT

As shown in Fig. 5, immobility time similarly increased in all groups between sessions $(H=5.17, p=0.16)$ and no differences among groups were found in the duration of immobility during the test session $(H=0.33, p=0.95)$.
These findings indicate that in aged mice the reexposure to an aversive condition induced a despair response affected by neither the cholinergic depletion nor the n-3 PUFA treatment.

\section{Morphological analyses}

Considering the fact that in mice adult neurogenesis is predominant in the dorsal hippocampus respect to the ventral hippocampus [101-104] and that the neurodegenerative AD-like syndrome affects at a first stage the dorsal hippocampus and the dorsal hippocampusdependent spatial learning and memory functions [105107], we decided to analyze volume, neurogenesis, and astrogliosis parameters in the dorsal horn of the hippocampus.

\section{Hippocampal volume}

In the dorsal region of the hippocampus, n-3 PUFA supplementation induced a significant volume preserving in both sham (mean and S.E.; sham oil $=3.12 \pm 0.15 \mathrm{~mm}^{3}$;

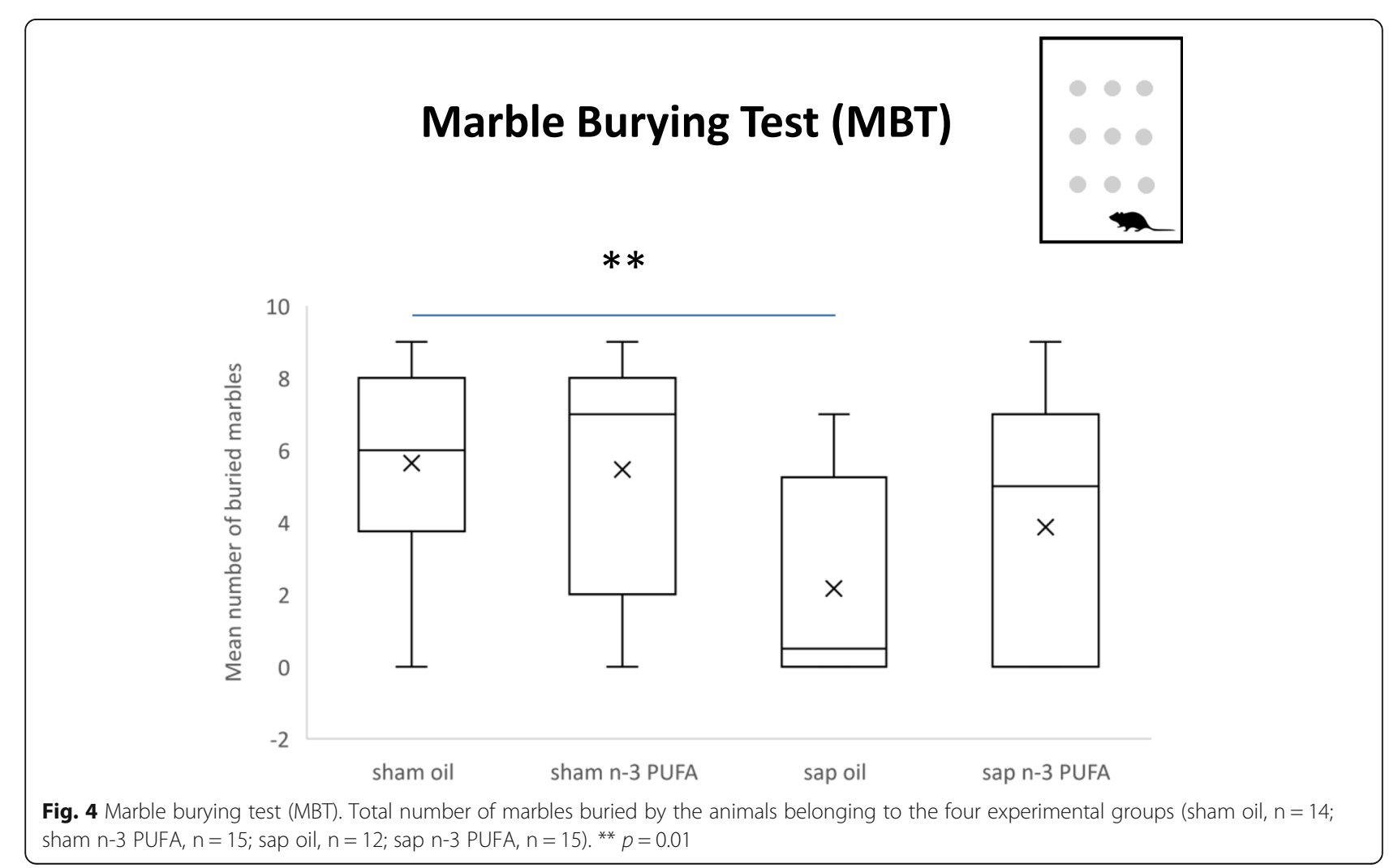


Table 1 Social interactions test (SIT). Results of the nonparametric analyses (Kruskal-Wallis ANOVA) on duration (s) of non-social and social behaviors observed in the four experimental groups during SIT

\begin{tabular}{ll}
\hline Non-social behaviors & \\
Exploration & $H=4.70, p=0.19$ \\
Rearing and wall-rearing & $H=7.16, p=0.07$ \\
Sniffing & $H=1.48, p=0.69$ \\
Digging & $H=2.30, p=0.51$ \\
Self-grooming & $H=5.21, p=0.16$ \\
Sum of non-social behaviors & $H=1.36, p=0.71$ \\
Social behaviors & \\
Following & $H=1.15, p=0.76$ \\
Head sniffing & $H=0.79, p=0.85$ \\
Body sniffing & $H=4.45, p=0.22$ \\
Ano-genital sniffing & $H=1.16, p=0.76$ \\
Sum of social behaviors & $H=2.38, p=0.50$ \\
\hline
\end{tabular}

sham $\mathrm{n}-3$ PUFA $=3.96 \pm 0.32 \mathrm{~mm}^{3}$; sham $\mathrm{n}-3$ PUFA vs. sham oil, $p=0.03$; Fig. 6a) and mu-p75-saporin lesioned groups (sap oil $=2.75 \pm 0.27 \mathrm{~mm}^{3}$; sap $\mathrm{n}-3$ PUFA $=4.1 \pm$ $0.43 \mathrm{~mm}^{3}$; sap n-3 PUFA vs. sap oil, $p=0.02$; Fig. $6 \mathrm{a}$ ). A similar volume increase has been observed in the CA1+ CA3 regions (sham oil $=0.36 \pm 0.02 \mathrm{~mm}^{3}$; sham $\mathrm{n}-3$ PUFA $=0.48 \pm 0.02 \mathrm{~mm}^{3}$; sap oil $=0.32 \pm 0.02 \mathrm{~mm}^{3}$; sap $\mathrm{n}-3$ PUFA $=0.47 \pm 0.01 \mathrm{~mm}^{3}$; sham $\mathrm{n}-3$ PUFA vs. sham oil, $p=0.02$; sap $\mathrm{n}-3$ PUFA vs. sap oil $p=0.04$; Fig. $6 \mathrm{~b}$ ) and DG (sham oil $=0.17 \pm 0.02 \mathrm{~mm}^{3}$; sham $\mathrm{n}-3$ PUFA $=$ $0.24 \pm 0.01 \mathrm{~mm}^{3} ; \quad$ sap oil $=0.14 \pm 0.04 \mathrm{~mm}^{3} ; \quad$ sap $\mathrm{n}-3$ PUFA $=0.25 \pm 0.03 \mathrm{~mm}^{3}$; sham $\mathrm{n}-3$ PUFA vs. sham oil, $p=0.04$; sap n-3 PUFA vs. sap oil, $p=0.04$; Fig. $6 \mathrm{c}$ ). No lesion effects were found on hippocampal volumes.

\section{Hippocampal neurogenesis}

\section{Neural stem cells (NSCs) and proliferation}

To analyze the effects of n-3 PUFA treatment on dorsal hippocampal neurogenesis, the proliferation and differentiation of newborn neurons were investigated in the four experimental groups. As for the proliferation analysis, the number of $\mathrm{BrdU}^{+}$proliferating progenitors in the DG was calculated. Saporin injection induced an evident although not significant increase in proliferation ( mean and S.E.; sham oil $=193.1 \pm 18.4$ BrdU $^{+}$cells; sap oil $=294 \pm 29.8 \mathrm{BrdU}^{+}$cells; sham oil vs. sap oil, $p=$ 0.08). Furthermore, n-3 PUFA administration induced significantly increased proliferation in both sham (sham n-3 PUFA $=375.6 \pm 40.6 \mathrm{BrdU}^{+}$cells) and immunotoxic lesioned groups (sap n-3 PUFA $=583.3 \pm 68.7 \mathrm{BrdU}^{+}$ cells; sham n-3 PUFA vs. sham oil, $p=0.001$; sap $\mathrm{n}-3$ PUFA vs. sap oil, $p=0.01$; Fig. $6 \mathrm{~d}, \mathrm{~h}$ ). Then, the subpopulations of NSCs/neural progenitors which contribute to the increased proliferation observed in the $n-3$
PUFA treated groups were evaluated by using two specific cell markers: SOX2, which is expressed in the NSCs and in the early differentiating progenitors, and DCX, a specific cell marker of late differentiating and postmitotic neuroblasts. A significant increase in $\mathrm{SOX}^{+}$ cells was found in both n-3 PUFA groups (sham n-3 PUFA $=20,616 \pm 384.2 \mathrm{SOX}^{+}$cells; sap $\mathrm{n}-3 \mathrm{PUFA}=24$, $168 \pm 553.4 \mathrm{SOX}^{+}$cells) with respect to their oil-treated counterparts (sham oil $=16,251 \pm 1229.2 \mathrm{SOX}^{+}$cells; sap oil $=16,560 \pm 427.53 \mathrm{SOX}^{+}$cells; sham $\mathrm{n}-3$ PUFA vs. sham oil, $p=0.01$; sap n-3 PUFA vs. sap oil, $p<$ 0.001; Fig. 6e, h), while the n-3 PUFA-dependent increase in $\mathrm{DCX}^{+}$cells was significant only in the immunotoxic lesioned group (sap oil $=177.8 \pm 39.3 \mathrm{DCX}^{+}$ cells; sap $n-3$ PUFA $=408.6 \pm 33 D^{2} X^{+}$cells; sap $n-3$ PUFA vs. sap oil, $p<0.007$; Fig 6f).

\section{Astrogliosis}

To assess a putative anti-inflammatory role of n-3 PUFA treatment, the number of $\mathrm{GFAP}^{+}$cells in the DG of the four experimental groups was measured. Cholinergic depletion induced a significant increase in $\mathrm{GFAP}^{+}$cells (sham oil $=8552.7 \pm 689 \mathrm{GFAP}^{+}$cells; sap oil $=11,476 \pm$ 883.2 $\mathrm{GFAP}^{+}$cells, sap oil vs. sham oil, $p=0.02$ ), which was interestingly counteracted by the n-3 PUFA treatment (sap n-3 PUFA $=8312.7 \pm 761.9$ GFAP $^{+}$cells; sap n-3 PUFA vs. sap oil, $p=0.01$; Fig. $6 \mathrm{~g}$ ).

\section{Biochemical analyses}

To examine whether the n-3 PUFA exert an antiinflammatory activity in our mouse model, we analyzed the hippocampal GFAP levels (Fig. 7a, b). The two-way ANOVA showed significant lesion effects, and significant diet $\mathrm{x}$ lesion interaction (lesion: $F_{1,12}=139.4, p<$ 0.0001; diet: $F_{1,12}=3.65, p=0.08$; diet $\mathrm{x}$ lesion: $F_{1,12}=$ 7.32, $p=0.02$ ). In particular, post-hoc comparisons showed that saporin-lesioned mice treated with $n-3$ PUFA showed reduced levels of GFAP, compared to oiltreated animals, whereas n-3 PUFA had no effect on sham-lesioned mice (sham oil vs. sap oil and sap n-3 PUFA, $p<0.0001$; sham $\mathrm{n}-3$ PUFA vs. sap oil, $p<0.0001$; sham n-3 PUFA vs. sap n-3 PUFA, $p=0.0002$; sap oil vs. sap n-3 PUFA, $p=0.03$ ).

Lesion verification through immunoblot analysis indicate an extensive reduction of VAChT in the hippocampus of both saporin-lesioned mice (lesion: $F_{1,12}=41.98$, $p<0.0001$; diet: $F_{1,12}=0.88, p=0.37$; lesion $\mathrm{x}$ diet: $F_{1,12}=1.56, p=0.23$; Fig. 7a, c).

Collectively, these findings prove that in the presence of a massive hippocampal cholinergic terminal loss, n-3 PUFA treatment was able to blunt hippocampal astrogliosis in aged mice. 


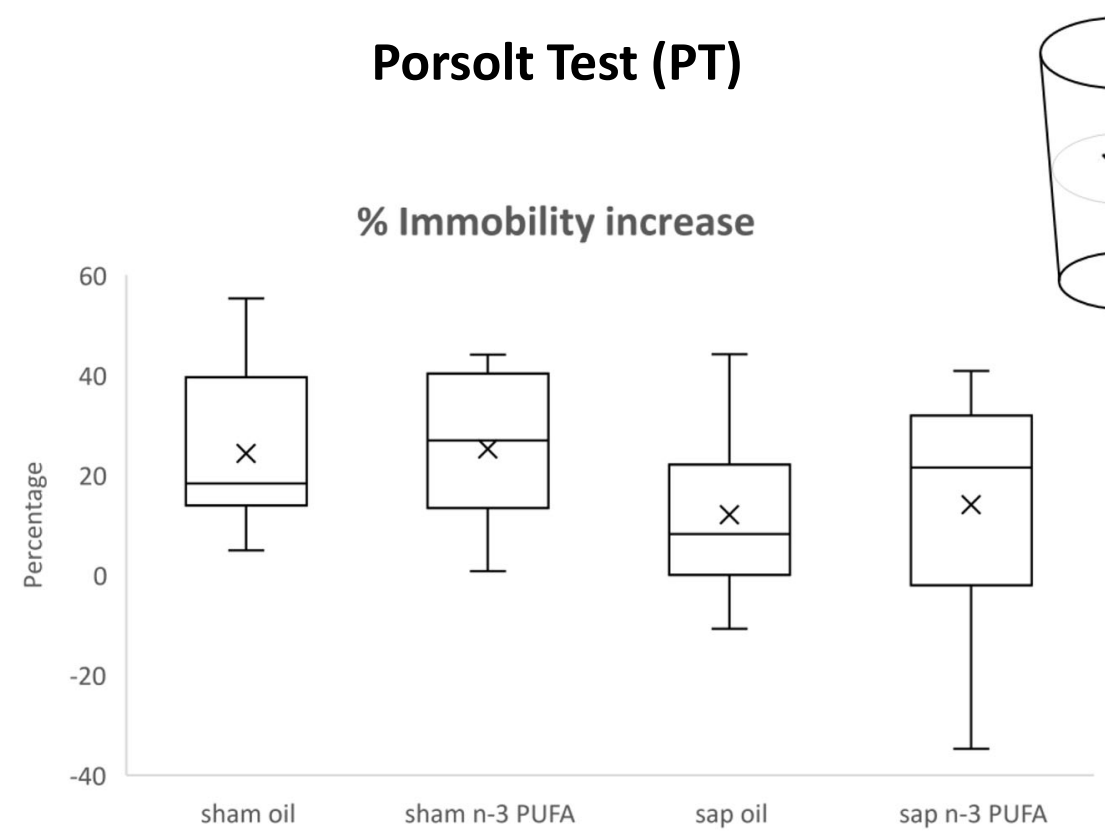

Immobility

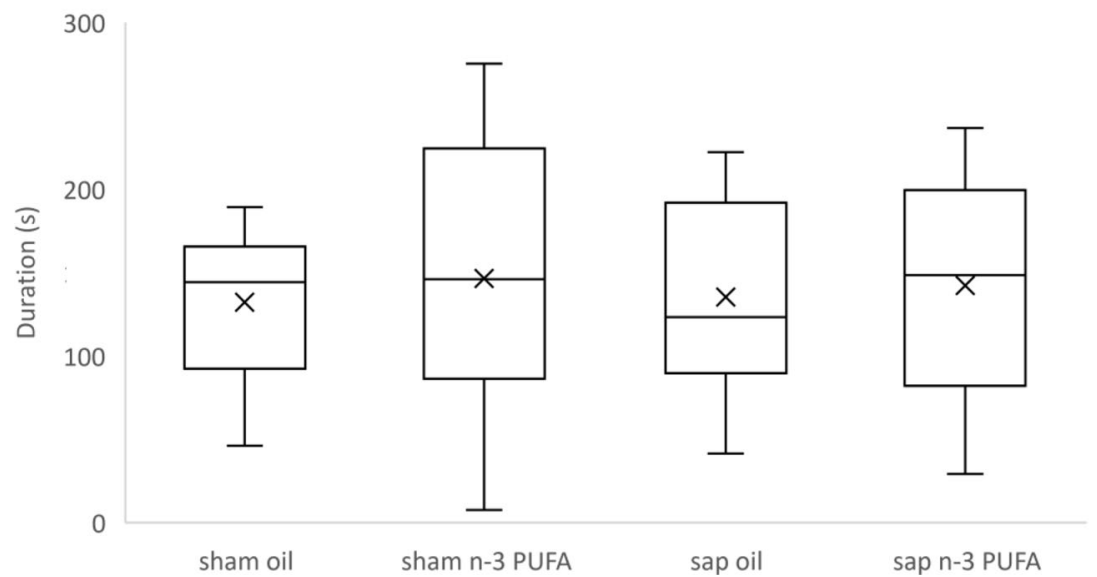

Fig. 5 Porsolt test (PT). Percentual increase in immobility displayed between test session and pre-test session and duration (s) of immobility during the test session displayed by the four experimental groups (sham oil, $n=10$; sham $n-3$ PUFA, $n=14$; sap oil, $n=11$; sap $n-3$ PUFA, $n=12$ )

\section{Lipid analysis}

\section{n-3 PUFA brain levels}

The total amount of EPA+DHA+DPA in the brain of all experimental groups was measured (sham oil, $n=5$; sham $n-3$ PUFA, $n=4$; sap oil, $n=3$; sap $n-3$ PUFA, $n=$ 3; Suppl. Table 2). It tended to increase in n-3 PUFAtreated groups in comparison to oil-treated groups $(U=$ $11, p=0.049)$. No significant correlations of EPA+DHA+ DPA levels with anxiety parameters (difference in time spent in closed vs. open arms in EPM: $r=-0.12, p=$ 0.68 ; number of buried marbles in MBT: $r=-0.06, p=$
0.83) were evident. Interestingly, a significant positive correlation was found between EPA+DHA+DPA levels and the discrimination index in NORT $(r=0.56, p=$ 0.03; Fig. 8), suggesting an important role of $n-3$ PUFA brain concentrations as putative predictors of reduced cognitive deterioration during aging.

\section{Discussion}

Nowadays, the necessity to increase our understanding of cognitive decline that characterizes the aging process and to develop new strategies for delaying and/or 
A Hippocampal Volume

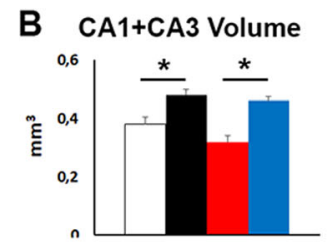

C DG Volume
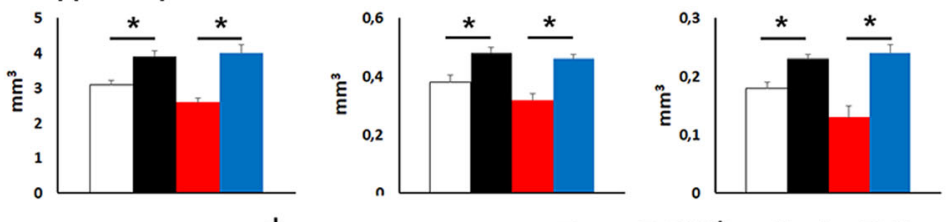

$\square$ sham oil

- sham n-3 PUFA

- sap oil

- sap n-3 PUFA

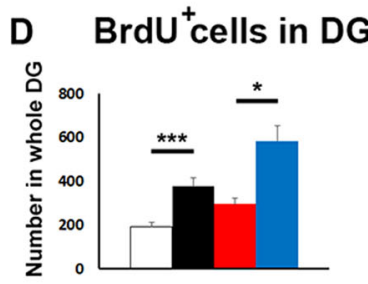

\section{E DCX cells in DG}

(1)
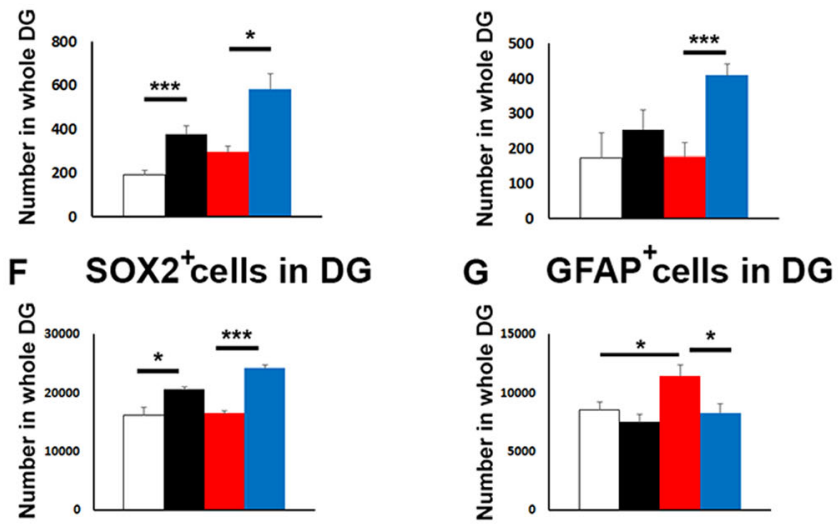

H SHAM n-3 PUFA

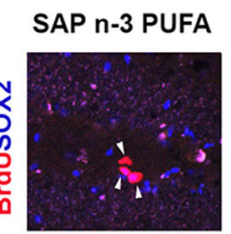

Fig. 6 Morphological analyses. a-c Graphs showing the variations of volume in the whole hippocampus, CA1+CA3, and dentate gyrus (DG) in the four experimental groups. $\mathbf{d}$ Graph showing the large increase of BrdU ${ }^{+}$cells in n-3 PUFA (sham and sap) groups when compared to their relative oil groups. e Graph representing the increased number of SOX2 ${ }^{+}$sub-population in the n-3 PUFA (sham and sap) groups in respect to their relative oil groups. $\mathbf{f}$ Graph showing the enhancement of DCX+ neuroblasts in sap n-3 PUFA group in comparison with sap oil group. $\mathbf{g}$ Graph indicating the increased number of GFAP ${ }^{+}$cells in sap oil vs. sham oil mice and the decreased number of GFAP ${ }^{+}$cells in sap n-3 PUFA vs. sap oil mice. $\mathbf{h}$ Representative images showing the increase of the BrdU ${ }^{+}$cells (indicated by arrowheads) in the DG of the sham $n-3$ PUFA and sap n-3 PUFA groups. Scale bar $100 \mu \mathrm{m} .{ }^{*} p<0.05,{ }^{* * *} p<0.001$. DG, dentate gyrus

treating age-related neurodegenerative diseases, like $\mathrm{AD}$, is becoming ever more urgent. $\mathrm{AD}$ is presently the most frequent, severe, and debilitating form of dementia worldwide $[11,108]$. Its prevalence rises exponentially with age producing a huge burden on healthcare costs [24] and only palliative pharmacological treatments (inevitably accompanied by side effects) are now available [22-24].

Once the $\mathrm{AD}$ pathological cascade leading to neuronal death has started, delaying the neuronal loss is extremely difficult. The lack of resolutive treatments to halt AD makes thus the promotion of healthy lifestyles an alternative favorable approach to preserve neuronal populations in the aging brain for as long as possible. To this aim, one point essential for neuronal health and functionality is to reach an optimal supply of nutrients. Remarkably, over the past several years, mechanistic, epidemiologic, and interventional studies have demonstrated n-3 PUFA beneficial effects against brain aging and age-related cognitive decline $[29,30,33,41]$, with the most consistent effects against $A D$ confined especially in the early or prodromal stages of the pathology [36, 48, 51, 52]. As an additional benefit, n-3 PUFA represent a low-cost, safe, and well-tolerated tool, without side effects for recommended doses [52].

In order to promote "nutrigeroprotective" interventions [109] for elderly affected by early $A D$, in the present study, we sought to further explore the neuroprotective potential of $n-3$ PUFA after the onset of a selective cholinergic depletion, which is retained to constitute one of the principal AD pathological events [53]. For this purpose, we examined whether the administration of n-3 PUFA after mu-p75-saporin lesions in aged mice could alleviate behavioral, morphological, and/or biochemical deficits.

Our results indicate an effective impact of n-3 PUFA in counteracting some functional and morphological deficits following cholinergic depletion and demonstrate increased regenerative patterns and decreased neuroinflammative components as possible underpinnings of the reduced cognitive decline and the concomitant reduced neuronal loss, even at old age. 


\section{A. Immunoblots}

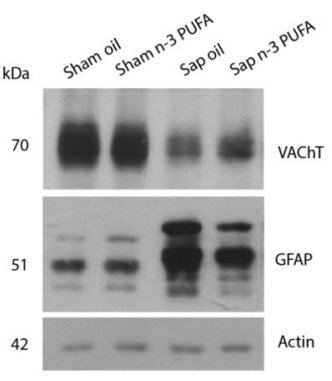

B. Hippocampal astrogliosis

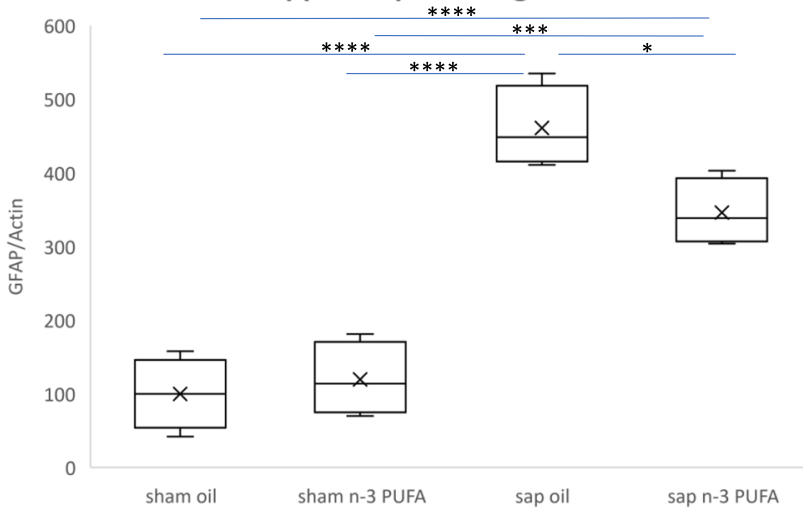

C. Lesion verification

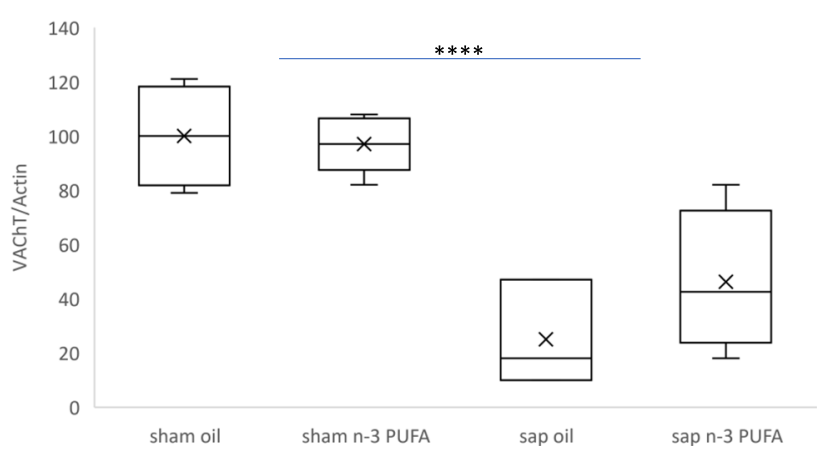

Fig. 7 Hippocampal GFAP and VAChT immunoblotting results. a The figure shows representative immunoblot of total hippocampal proteins from the four experimental groups. b, c The histogram shows densitometric quantification of GFAP (b) or VAChT (c) changes in gray values, expressed as \% of sham oil group. Data of the four experimental groups are depicted as mean and S.E., actin was used as loading control. (GFAP analysis: $n=4$ per group; VAChT analysis: sham oil, $n=4$; sham $n-3$ PUFA, $n=5$; sap oil, $n=3$; sap $n-3$ PUFA, $n=4$ ). Statistical significance of the post-hoc comparisons between sap oil and the remaining groups: ${ }^{*} p<0.05 ;{ }^{* * *} p<0.001$; ${ }^{* * *} p<0.0001$ )

\section{Correlation between object recognition and $n-3$ PUFA brain levels}

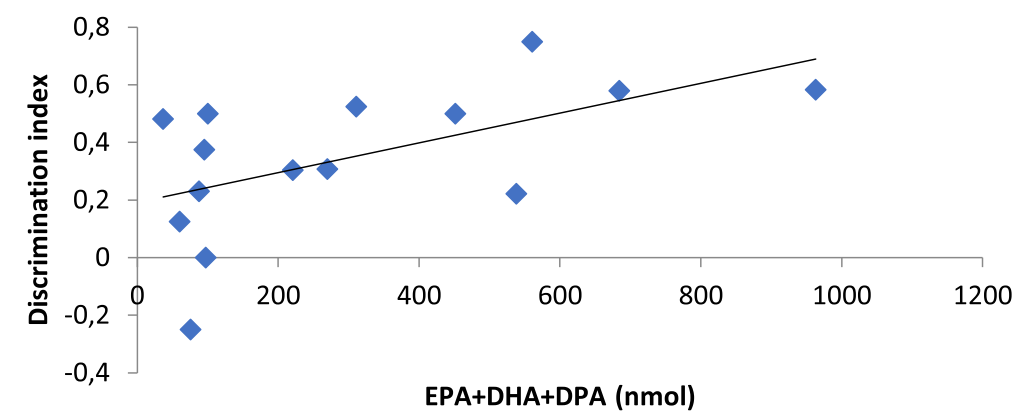

Fig. 8 Correlation between object recognition and n-3 PUFA brain levels. Scatterplot representing the relationship between the discrimination index in NORT and total n-3 PUFA brain levels 
Specifically, in sham-lesioned aged mice, the n-3 PUFA supplementation did not provoke any behavioral modification, apart from a reduced horizontal and vertical exploration during NORT that was present also in the saporin-lesioned mice treated with n-3 PUFA and could concur to a reduced stress response to novelty, as described elsewhere [110, 111]. Moreover, n-3 PUFA preserved hippocampal volumes and increased the proliferation of newborn neurons in the DG of shamlesioned mice, in line with the few previous findings on aged mice [63, 64, 112, 113]. Astrogliosis levels were unaffected by $n-3$ PUFA treatment in sham-lesioned aged mice.

The cholinergic depletion per se induced anxiolytic effects and novelty recognition memory impairments in aged mice, without modifying social behaviors and passive coping responses. These behavioral results are in agreement with the reduction of anxiety [114, 115] and the presence of object recognition memory deficits [115-118] previously reported following cholinergic immunotoxic lesions in adult rodents. The anxiolytic pattern of our cholinergically depleted aged mice is also consistent with the increased exploration of open spaces in the EPM and reduced hiding in the MBT observed in mice with temporary and reversible inhibition of cholinergic neurons in the medial septum [67]. As for social interaction, it was scarce in our aged mice, as expected at late stage of life in rodents $[65,76,119]$, and it was unaffected by the cholinergic lesion possibly due to a floor effect and/or to the sparing of striatal circuits linked to the rewarding properties of affiliative behaviors $[54,120,121]$. Regarding depressive-like responses, to our knowledge, this is the first study evaluating the performance of cholinergically depleted aged mice by using a two-session PT. We found no effect of cholinergic depletion on the increase in passive behavioral coping elicited by the re-exposure to the inescapable situation [122]. This finding is probably linked to a saporin lack of action on the dopaminergic accumbens/prefrontal networks which modulate stress coping and adaptation, in complementary fashion with mineralocorticoid and glucocorticoid receptors in the limbic brain [122, 123].

As for morphological and biochemical correlates, the cholinergic lesion increased hippocampal astrogliosis in agreement with similar findings in cholinergically depleted adult rats $[107,124]$ and aged mice [56], as well as in $\mathrm{AD}$ patients [125]. In the present study, we did not find any effect of the immunotoxic cholinergic lesion on hippocampal neurogenesis, in line with previous research in adult [126] and aged [56] mice. Hippocampal volumes were not significantly affected by the cholinergic lesion.

Remarkably, n-3 PUFA post-lesional supplementation regulated the anxiety alterations and reverted the novelty recognition memory impairment induced by the cholinergic depletion in aged mice. Similar beneficial effects of n-3 PUFA treatment on anxiety and novelty recognition memory have been demonstrated in other animal models during adulthood and aging [63, 72, 127-138].

The emotional and cognitive ameliorations here observed were complemented and supported by the increased n-3 PUFA brain levels and the modified hippocampal morphological features. Namely, in saporin-lesioned mice treated with n-3 PUFA, we detected preserved hippocampal volumes, increased proliferating cells and immature neurons in the DG, and diminished hippocampal astrogliosis with respect to control lesioned mice.

The n-3 PUFA efficacy in counteracting the age-related brain atrophy has been previously well-documented in rodent $[28,63,64]$ and human [130-133] investigations. A preventive n-3 PUFA action against hippocampal neuronal loss has been already observed in aged mice when the n-3 PUFA administration preceded the cholinergic depletion [56]. Such an action may be attributed to n-3 PUFA positive influence in helping neurons to cope with aging by potentiating synaptogenesis and reducing apoptosis and glial degeneration $[29,56,63]$.

In our study, the n-3 PUFA stimulation of neuronal progenitor proliferation (i.e., $\mathrm{BrdU}^{+}$and $\mathrm{SOX}_{2}{ }^{+}$cells) in the DG occurred after both sham and saporin lesions in aged mice, but the increase in neuronal differentiation of newborn neurons (i.e., $\mathrm{DCX}^{+}$cells) persisted only after the immunotoxic lesion, probably to compensate for the cholinergic neuronal loss. Similar neurogenic effects of $\mathrm{n}-3$ PUFA have been reported also in one of our previous studies [56], in which n-3 PUFA supplementation was administered in aged mice before cholinergic depletion. Notably, in case of traumatic brain injury $[134,135]$ and cerebral ischemia $[136,137]$, hippocampal neurogenesis is stimulated in order to recruit compensatory neural networks and to preserve the functions affected by the lesion. Further, in transgenic AD mice and in AD patients, hippocampal neurogenesis is increased either in response to the impaired neurotransmission and to disease-induced neuronal loss $[138,139]$.

Finally, although adult neurogenesis tends to decline with age [140], it is regulated by several extracellular cues, including hormones, growth factors, and neurotransmitters [141], such as acetylcholine [142-144]. Interestingly, n-3 PUFA enhancement of cholinergic transmission and neuronal membrane fluidity are both important modulators of neurogenesis $[1,3,145,146]$.

Anyhow, the neurogenic potential of n-3 PUFA may constitute the structural basis of the maintained mnesic performance of sap n-3 PUFA mice by virtue of the multiple implications of the hippocampal neurogenesis in mnesic retention $[128,147]$. 
The n-3 PUFA-induced increase in neurogenesis as well as the hippocampal volume preserving occurred in the context of a decreased hippocampal astrogliosis. We focused on astrocytes since they constitute the most abundant type of neuroglial cells, have a key role in synaptic regulation (acting on formation, maturation, maintenance, pruning, and remodeling of synapses during aging and diseases) [148-151], and are well-characterized in aged humans [21, 152-154]. Aging may trigger the loss of normal function in astrocytes, which causes an intensified inflammatory state [155]. Moreover, AD brains are additionally characterized by a prominent reactive astrogliosis due to the progressive neurodegeneration [156]. In this study, while the hippocampal astrogliosis was detrimentally enhanced by the cholinergic depletion, the n-3 PUFA supplementation exerted a neuroprotective and antiinflammatory role by lowering the increased astrogliosis hippocampal levels, in line with previous studies in aged subjects $[29,56,63,157]$. However, we cannot exclude the involvement of microglia and oligodendroglia $[158,159]$ in modulating the n-3 PUFA effects on saporin lesions. In fact, there are strict functional neuroglial interactions; hence, after brain injury and in neurodegenerative disorders, the activated microglia may induce reactive astrocytosis which in turn drives death of neurons and oligodendrocytes [151].

Importantly, several dietary components (such as n-3 PUFA, antioxidants, and polyphenols) consumed in antiinflammatory dietary patterns associated with slower rate of cognitive decline (such as Mediterranean diet) are reported to be able to inhibit neuroinflammation associated with $A D$ via several immune pathways within the brain and indirectly from the gut microbiome and systemic circulation [160]. For example, fish-derived long chain n-3 PUFA may reduce the expression of pro-inflammatory cytokines in microglia and support resolution of inflammation in the brain [161, 162]. Moreover, in line with our findings, other studies on prodromal manifestations of $A D$, such as $A \beta$ - or $n-3$ PUFA deficiency-induced depressive-like phenotypes, demonstrated that n-3 PUFA modulate neuroinflammatory activation pathways, especially in the hippocampal circuits $[163,164]$.

\section{Limitations}

The first limitation of the present study may be the lack of young groups of mice lesioned and treated as the aged ones to also evaluate the age effect. For example, in the SIT, we found no significant effects of lesion or diet, but we can only hypothesize a floor effect linked to an agerelated decrease in social interest based on previous studies in rodents $[65,76,119]$. It should be pointed out, however, that i.c.v. injections of the mu-p75-saporin in aged mice allow analyzing how the aging brain (and not the young one) reacts to the cholinergic depletion. Thus, since the majority of people with AD are older than 65 years, the use of aged animals does increase the translational power of the present study.

Secondly, we are aware that the use of aged mice exposes to the risk of an obvious reduction of the sample size, as the experiment goes by, due to increased mortality rate, especially following surgery. Therefore, we have a reduced number of measurements in some experimental groups, as for example in the n-3 PUFA brain levels and PT. Differently, the reduced number of subjects for SIT (in comparison to the other behavioral tasks) was due to video recording troubles, while the exclusion of some animals from NORT was due to the failure to meet the contact time criterion, maybe linked to the age-related reduced interest of aged animals also for inanimate stimuli [119]. Anyway, the overall sample size of the present study was calculated on the basis of power analysis and is comparable to our previous studies in which we performed similar behavioral, morphological, and biochemical analyses $[56,63]$.

A final potential limitation of the present study could have been that the animals received a prolonged $n-3$ PUFA supplementation via gavage. However, we feel to exclude any potential detrimental effect of it, since we previously demonstrated that 8 weeks of gavage did not modify the behavioral, morphological, and biochemical measurements in untreated naïve aged mice [63].

\section{Conclusions}

The n-3 PUFA treatment represents a form of neuroplasticity promoter even at old age and in the presence of a massive cholinergic loss, thus supporting their use to delay $\mathrm{AD}$ pathology progression. Moreover, the discovery of a strict link between preserved hippocampal volume and neurogenesis and reduced astrogliosis as underpinnings of maintained cognitive and behavioral performances during aging shed new light on the n-3 PUFA mechanisms of action.

\section{Supplementary information}

Supplementary information accompanies this paper at https://doi.org/10. 1186/s13195-020-00705-3.

\section{Additional file 1: Suppl. Table 1. NORT object preference, grooming and defecation data. Mean and S.E. of the following NORT parameters in the four experimental groups: preference for one of the two identical objects during the training trial (percentage of contact time with object A/total contact time with object A + object B); preference for the novel object during the test trial (percentage of contact time with the novel object/total contact time with the novel object + familiar object); grooming time (s) and number of defecations in all task trials. \\ Additional file 2: Suppl. Table 2. Brain levels of n-3 PUFA. Mean and S.E. of EPA + DHA + DPA brain levels in the four experimental groups.}

\section{Abbreviations}

AD: Alzheimer's disease; ALA: Alpha-linolenic acid; AB: Amyloid- $\beta$; AP: Anteroposterior coordinate; BrdU: Bromodeoxyuridine; CA: Cornu Ammonis 
(Ammon's Horn); DAPI: 4',6-Diamidino-2-phenylindole; DCX: Doublecortin; DG: Dentate gyrus; DHA: Docosahexaenoic acid; DPA: Docosapentaenoic acid; DV: Dorso-ventral coordinate; EPA: Eicosapentaenoic acid; EPM: Elevated plus maze; GFAP: Glial fibrillary acidic protein; i.c.v.: Intracerebroventricular; MBT: Marble burying test; MCl: Mild cognitive impairment; ML: Medio-lateral coordinate; n-3: PUFA omega-3 polyunsaturated fatty acids; NCl: Negative chemical ionization mode; NORT: Novel object recognition task; NSCs: Neural stem cells; p75NTR: p75 neurotrophin receptor; PBS: Phosphate buffer; PFA: Paraformaldehyde; PT: Porsolt test; Saporin: mu-p75-saporin; SIM: Selected ion monitoring; SIT: Social interactions test; SOX2: Sexdetermining region Y-box 2; VAChT: Vesicular acetylcholine transporter

\section{Acknowledgements}

The present research has been supported by grants from the Italian Ministry of Health (Young Investigator's Award: GR-2011-02351086 to D.C.; Ricerca Corrente to L.P.). M.D.A. was supported by grants from the Italian Ministry of Health (Research Grant: RF-2018-12365527) and from the Alzheimer's Association (Grant: AARG-18-566270). L. Pi was supported by $5 \times 1000$ from Italian Ministry of Health to IRCCS Fondazione Santa Lucia (2017).

\section{Authors' contributions}

D.C., L.P., and S.F.-V. designed the study; P.D.B. and D.C. performed the surgery; D.C., E.L., S.S., D.Ch., and F.R.D.A. performed the behavioral analyses; S.F.-V performed the histological analyses and contributed in writing the manuscript; A.N. performed the biochemical analyses and contributed in writing the manuscript; L.Pi., M.R., and F.M.D.C. performed the lipid analyses; L.P., S.F.V., L.Pi., M.R., and A.N. analyzed and interpreted data; D.C. and L.P. drafted the manuscript. D.C., S.F.-V., and L.P. revised the manuscript. All authors read and approved the final manuscript.

\section{Funding}

This research was funded by the Italian Ministry of Health, grant number GR2011-02351086 (to D.C.) and Ricerca Corrente (to L.P.), and by the Alzheimer's Association, grant number AARG-18-566270 (to M.D.A.)

\section{Availability of data and materials}

Analyses of all data produced during this study are included in the article (and its supplementary information files). Datasets will be available from the corresponding author on reasonable request.

\section{Ethics approval and consent to participate}

All animal experiments were performed in accordance with the European Union Directive of September 22, 2010 (2010/63/EU), and approved by the Italian Ministry of Health (Legislative Decree No 682/2016).

\section{Consent for publication}

Not applicable.

\section{Competing interests}

The authors declare that they have no competing interests.

\section{Author details}

'IRCCS Fondazione Santa Lucia, Rome, Italy. ${ }^{2}$ University of Rome "Sapienza", Rome, Italy. "University "Campus Bio-Medico", Rome, Italy. "Department of Human Sciences, Guglielmo Marconi University, Rome, Italy. Institute of Biochemistry and Cell Biology, CNR, Monterotondo, Italy. Università Cattolica del Sacro Cuore, Rome, Italy. IRCCS Fondazione Policlinico Universitario Agostino Gemelli, Rome, Italy. ${ }^{8}$ Department of Pharmacy, University G. D'Annunzio of Chieti-Pescara, Chieti, Italy.

Received: 30 June 2020 Accepted: 12 October 2020 Published online: 16 November 2020

\section{References}

1. Su HM. Mechanisms of n-3 fatty acid-mediated development and maintenance of learning memory performance. J Nutr Biochem. 2010;21: 364-73

2. Denis I, Potier B, Vancassel S, Heberden C, Lavialle M. Omega-3 fatty acids and brain resistance to ageing and stress: body of evidence and possible mechanisms. Ageing Res Rev. 2013;12:579-94.
3. Luchtman DW, Song C. Cognitive enhancement by omega-3 fatty acids from child-hood to old age: findings from animal and clinical studies. Neuropharmacology. 2013;64:550-65.

4. Denis I, Potier B, Heberden C, Vancassel S. Omega-3 polyunsaturated fatty acids and brain aging. Curr Opin Clin Nutr Metab Care. 2015;18:139-46.

5. Innis SM. Dietary (n-3) fatty acids and brain development. J Nutr. 2007;137: 85-9.

6. Nichols PD, Petrie J, Singh S. Long-chain omega-3 oils-an update on sustainable sources. Nutrients. 2010;2:572-85.

7. Yehuda S. Polyunsaturated fatty acids as putative cognitive enhancers. Med Hypotheses. 2012;79:456-61.

8. Grosso G, Galvano F, Marventano S, Malaguarnera M, Bucolo C, Drago F et al. Omega-3 fatty acids and depression: scientific evidence and biological mechanisms. Oxidative Med Cell Longev. 2014;2014:313570.

9. Tsujiguchi H, Nguyen TT, Goto D, Miyagi S, Kambayashi Y, Hara A, et al. Relationship between the intake of $n-3$ polyunsaturated fatty acids and depressive symptoms in elderly Japanese people: differences according to sex and weight status. Nutrients. 2019;11:775.

10. Kumar A, Singh A, Ekavali. A review on Alzheimer's disease pathophysiology and its management: an update. Pharmacol Rep 2015;69:195-203.

11. Sengoku R. Aging and Alzheimer's disease pathology. Neuropathology. 2020;40:22-9.

12. Scheltens $P$, Blennow K, Breteler MMB, de Strooper B, Frisoni GB, Salloway S, et al. Alzheimer's disease. Lancet. 2016;388:505-17.

13. Deture MA, Dickson DW. The neuropathological diagnosis of Alzheimer's disease. Mol Neurodegener. 2019;14:1-18.

14. Serrano-Pozo A, Frosch MP, Masliah E, Hyman BT. Neuropathological alterations in Alzheimer disease. Cold Spring Harb Perspect Med. 2011;1: a006189.

15. Crews L, Masliah E. Molecular mechanisms of neurodegeneration in Alzheimer's disease. Hum Mol Genet. 2010;19:R12-20.

16. Bonner-Jackson A, Mahmoud S, Miller J, Banks SJ. Verbal and non-verbal memory and hippocampal volumes in a memory clinic population. Alzheimers Res Ther. 2015:7:61.

17. Blanken AE, Hurtz S, Zarow C, Biado K, Honarpisheh H, Somme J, et al. Associations between hippocampal morphometry and neuropathologic markers of Alzheimer's disease using 7 T MRI. Neurolmage Clin. 2017;15:56-61.

18. Ferreira D, Nordberg A, Westman E. Biological subtypes of Alzheimer disease: a systematic review and meta-analysis. Neurology. 2020;94:436-48.

19. Perry EK, Johnson M, Ekonomou A, Perry RH, Ballard C, Attems J. Neurogenic abnormalities in Alzheimer's disease differ between stages of neurogenesis and are partly related to cholinergic pathology. Neurobiol Dis. 2012;47:155-62

20. Maruszak A, Pilarski A, Murphy T, Branch N, Thuret S. Hippocampal neurogenesis in Alzheimer's disease: is there a role for dietary modulation? Alzheimers Dis. 2014;38:11-38.

21. Moreno-Jiménez EP, Flor-García M, Terreros-Roncal J, Rábano A, Cafini F, Pallas-Bazarra N, et al. Adult hippocampal neurogenesis is abundant in neurologically healthy subjects and drops sharply in patients with Alzheimer's disease. Nat Med. 2019;25:554-60.

22. Pepeu G, Giovannini M. Cholinesterase inhibitors and beyond. Curr Alzheimer Res. 2009;6:86-96.

23. Ferreira-Vieira TH, Guimaraes IM, Silva FR, Ribeiro FM. Alzheimer's disease: targeting the cholinergic system. Curr Neuropharmacol 2016;14:101-115.

24. Liu PP, Xie $Y$, Meng XY, Kang JS. History and progress of hypotheses and clinical trials for Alzheimer's disease. Signal Transduct Target Ther. 2019:4:29.

25. Davtyan H, Hovakimyan A, Kiani Shabestari S, Antonyan T, Coburn MA, Zagorski $\mathrm{K}$, et al. Testing a MultiTEP-based combination vaccine to reduce $A \beta$ and tau pathology in Tau22/5xFAD bigenic mice. Alzheimers Res Ther 2019;11:107.

26. Barnes DE, Yaffe $K$. The projected effect of risk factor reduction on Alzheimer's disease prevalence. Lancet Neurol. 2011;10:819-28.

27. Hashimoto M, Hossain S. Neuroprotective and ameliorative actions of polyunsaturated fatty acids against neuronal diseases: beneficial effect of docosahexaenoic acid on cognitive decline in Alzheimer's disease. J Pharmacol Sci. 2011;116:150-62.

28. Hooijmans CR, Pasker-De Jong PCM, De Vries RBM, Ritskes-Hoitinga M. The effects of long-term omega-3 fatty acid supplementation on cognition and Alzheimer's pathology in animal models of Alzheimer's disease: a systematic review and meta-analysis. J Alzheimers Dis. 2012;28:191-209. 
29. Cutuli D. Functional and structural benefits induced by omega-3 polyunsaturated fatty acids during aging. Curr Neuropharmacol. 2017;15: 534-42.

30. Zhou MM, Ding L, Wen M, Che HX, Huang JQ, Zhang $T$, et al. Mechanisms of DHA-enriched phospholipids in improving cognitive deficits in aged SAMP8 mice with high-fat diet. J Nutr Biochem. 2018:59:64-75.

31. Beydoun MA, Kaufman JS, Satia JA, Rosamond W, Folsom AR. Plasma n-3 fatty acids and the risk of cognitive decline in older adults: the atherosclerosis risk in communities study. Am J Clin Nutr. 2007;85:1103-11.

32. Whalley LJ, Deary IJ, Starr JM, Wahle KW, Rance KA, Bourne VJ, et al. n-3 Fatty acid erythrocyte membrane content, APOE $\varepsilon 4$, and cognitive variation: an observational follow-up study in late adulthood. Am J Clin Nutr. 2008;87: 449-54.

33. Samieri C, Morris MC, Bennett DA, Berr C, Amouyel P, Dartigues JF, et al. Fish intake, genetic predisposition to Alzheimer disease, and decline in global cognition and memory in 5 cohorts of older persons. Am J Epidemiol. 2018:187:933-40.

34. Cunnane SC, Plourde M, Pifferi F, Bégin M, Féart C, Barberger-Gateau P. Fish, docosahexaenoic acid and Alzheimer's disease. Prog Lipid Res. 2009;48:239-56.

35. Samieri C, Féart C, Proust-Lima C, Peuchant E, Dartigues JF, Amieva H, et al. Omega-3 fatty acids and cognitive decline: modulation by ApoEع4 allele and depression. Neurobiol Aging. 2011;32(2317):e13-22.

36. Otaegui-Arrazola A, Amiano P, Elbusto A, Urdaneta E, Martínez-Lage P. Diet, cognition, and Alzheimer's disease: food for thought. Eur J Nutr. 2014;53:1-23.

37. Zhang XW, Hou WS, Li M, Tang ZY. Omega-3 fatty acids and risk of cognitive decline in the elderly: a meta-analysis of randomized controlled trials. Aging Clin Exp Res. 2016;28:165-6.

38. Chiu CC, Su KP, Cheng TC, Liu HC, Chang CJ, Dewey ME, et al. The effects of omega-3 fatty acids monotherapy in Alzheimer's disease and mild cognitive impairment: a preliminary randomized double-blind placebo-controlled study. Prog Neuro-Psychopharmacol Biol Psychiatry. 2008;32:1538-44.

39. Yurko-Mauro K. Cognitive and cardiovascular benefits of docosahexaenoic acid in aging and cognitive decline. Curr Alzheimer Res. 2010;7:190-6.

40. Witte AV, Kerti L, Hermannstädter HM, Fiebach JB, Schreiber SJ, Schuchardt JP, et al. Long-chain omega-3 fatty acids improve brain function and structure in older adults. Cereb Cortex. 2014;24:3059-68.

41. Zhang Y, Chen J, Qiu J, Li Y, Wang J, Jiao J. Intakes of fish and polyunsaturated fatty acids and mild-to-severe cognitive impairment risks: a dose-response meta-analysis of 21 cohort studies. Am J Clin Nutr. 2016;103:330-40.

42. Van De Rest $O$, Wang $Y$, Barnes LL, Tangney $C$, Bennett DA, Morris MC. APOE e4 and the associations of seafood and long-chain omega-3 fatty acids with cognitive decline. Neurology. 2016;86:2063-70.

43. Baleztena J, Ruiz-Canela M, Sayon-Orea C, Pardo M, Añorbe T, Gost Jl, et al. Association between cognitive function and supplementation with omega3 PUFAs and other nutrients in 75 years old patients: a randomized multicenter study. PLoS One. 2018;13:e0193568.

44. Van De Rest O, Geleijnse JM, Kok FJ, Van Staveren WA, Dullemeijer C, OldeRikkert MGM, et al. Effect of fish oil on cognitive performance in older subjects: a randomized, controlled trial. Neurology. 2008;71:430-8.

45. Dangour AD, Allen E, Elbourne D, Fasey N, Fletcher AE, Hardy P, et al. Effect of 2-y n-3 long-chain polyunsaturated fatty acid supplementation on cognitive function in older people: a randomized, double-blind, controlled trial. Am J Clin Nutr. 2010;91:1725-32.

46. Quinn JF, Raman R, Thomas RG, Yurko-Mauro K, Nelson EB, Van Dyck C, et al. Docosahexaenoic acid supplementation and cognitive decline in Alzheimer disease: a randomized trial. JAMA - J Am Med Assoc. 2010;304:1903-11.

47. Geleijnse JM, Giltay EJ, Kromhout D. Effects of $n-3$ fatty acids on cognitive decline: a randomized, double-blind, placebo-controlled trial in stable myocardial infarction patients. Alzheimers Dement. 2012;8:278-87.

48. de Souza Fernandes DP, Canaan Rezende FA, Pereira Rocha G, De Santis Filgueiras M, Silva Moreira PR, Gonçalves Alfenas RdeC. Effect of eicosapentaenoic acid and docosahexaenoic acid supplementations to control cognitive decline in dementia and Alzheimer's disease: a systematic review. Nutr Hosp 2015;32:528-533.

49. Burckhardt M, Herke M, Wustmann T, Watzke S, Langer G, Fink A. Omega-3 fatty acids for the treatment of dementia. Cochrane Database Syst Rev. 2016:4:CD009002.

50. Araya-Quintanilla F, Gutiérrez-Espinoza H, Sánchez-Montoya U, Muñoz-Yañez MJ, Baeza-Vergara A, Petersen-Yanjarí M, et al. Effectiveness of omega-3 fatty acid supplementation in patients with Alzheimer disease: a systematic review and meta-analysis. Neurologia. 2020;35:105-14.
51. Canhada S, Castro K, Perry IS, Luft VC. Omega-3 fatty acids' supplementation in Alzheimer's disease: a systematic review. Nutr Neurosci. 2018;21:529-38.

52. Avallone R, Vitale G, Bertolotti M. Omega-3 fatty acids and neurodegenerative diseases: new evidence in clinical trials. Int J Mol Sci. 2019;20:4256.

53. Bartus RT. On neurodegenerative diseases, models, and treatment strategies: lessons learned and lessons forgotten a generation following the cholinergic hypothesis. Exp Neurol. 2000;163:495-529.

54. Moreau PH, Cosquer B, Jeltsch H, Cassel JC, Mathis C. Neuroanatomical and behavioral effects of a novel version of the cholinergic immunotoxin mu p75-saporin in mice. Hippocampus. 2008;18:610-22.

55. Petrosini L, De Bartolo P, Cutuli D, Gelfo F. Perinatal 192 igG-saporin as neuroteratogen. Curr Top Behav Neurosci. 2016;29:111-23.

56. Cutuli D, Landolfo E, Decandia D, Nobili A, Viscomi MT, La Barbera L, et al. Neuroprotective role of dietary supplementation with omega-3 fatty acids in the presence of basal forebrain cholinergic neurons degeneration in aged mice. Int J Mol Sci. 2020;21:1741.

57. Laursen B, Mørk A, Plath N, Kristiansen U, Bastlund JF. Cholinergic degeneration is associated with increased plaque deposition and cognitive impairment in APPswe/PS1dE9 mice. Behav Brain Res. 2013;240:146-52.

58. Paxinos G, Franklin KBJ. The mouse brain in stereotaxic coordinates. 2nd ed. USA: Elsevier Academic Press; 2004

59. Horrocks LA, Farooqui AA. Docosahexaenoic acid in the diet: its importance in maintenance and restoration of neural membrane function. Prostag Leukot Ess. 2004;70:361-72

60. Dyall SC. Long-chain omega-3 fatty acids and the brain: a review of the independent and shared effects of EPA. DPA and DHA Front Aging Neurosci. 2015;7:52.

61. Walf AA, Frye CA. The use of the elevated plus maze as an assay of anxietyrelated behavior in rodents. Nat Protoc. 2007;2:322-8.

62. Ruehle S, Remmers F, Romo-Parra H, Massa F, Wickert M, Wörtge S, et al. Cannabinoid CB1 receptor in dorsal telencephalic glutamatergic neurons: distinctive sufficiency for hippocampus-dependent and amygdaladependent synaptic and behavioral functions. J Neurosci. 2013;33:10264-77.

63. Cutuli D, de Bartolo P, Caporali P, Laricchiuta D, Foti F, Ronci M, et al. N-3 polyunsaturated fatty acids supplementation enhances hippocampal functionality in aged mice. Front Aging Neurosci. 2014;6:1-53.

64. Cutuli D, Pagani M, Caporali P, Galbusera A, Laricchiuta D, Foti F, et al. Effects of omega-3 fatty acid supplementation on cognitive functions and neural substrates: a voxel-based morphometry study in aged mice. Front Aging Neurosci. 2016;8:38.

65. Gorina YV, Komleva YK, Lopatina OL, Volkova W, Chernykh Al, Shabalova AA, et al. The battery of tests for behavioral phenotyping of aging animals in the experiment. Adv Gerontol. 2017;7:137-42.

66. Roni MA, Rahman S. Neuronal nicotinic receptor antagonist reduces anxiety-like behavior in mice. Neurosci Lett. 2011;504:237-41.

67. Zhang $Y$, Jiang $Y Y$, Shao S, Zhang C, Liu FY, Wan Y, et al. Inhibiting medial septal cholinergic neurons with DREADD alleviated anxiety-like behaviors in mice. Neurosci Lett. 2017;638:139-44.

68. Cohen SJ, Stackman RW. Assessing rodent hippocampal involvement in the novel object recognition task. A review Behav Brain Res. 2015;285:105-17.

69. Squire LR, Wixted JT, Clark RE. Recognition memory and the medial temporal lobe: a new perspective. Nat Rev Neurosci. 2007;8:872-83.

70. Jessberger S, Clark RE, Broadbent NJ, Clemenson GD, Consiglio A, Lie DC, et al. Dentate gyrus-specific knockdown of adult neurogenesis impairs spatial and object recognition memory in adult rats. Learn Mem. 2009;16: 147-54.

71. de Bruin N, Pouzet B. Beneficial effects of galantamine on performance in the object recognition task in Swiss mice: deficits induced by scopolamine and by prolonging the retention interval. Pharmacol Biochem Behav. 2006; 85:253-60.

72. Arsenault D, Julien C, Tremblay C, Calon F. DHA improves cognition and prevents dysfunction of entorhinal cortex neurons in 3xTg-AD mice. PLoS One. 2011;6:e17397.

73. Angoa-Pérez M, Kane MJ, Briggs DI, Francescutti DM, Kuhn DM. Marble burying and nestlet shredding as tests of repetitive, compulsive-like behaviors in mice. J Vis Exp. 2013;50978.

74. Wolmarans DW, Stein DJ, Harvey BH. Of mice and marbles: novel perspectives on burying behavior as a screening test for psychiatric illness. Cogn Affect Behav Neurosci. 2016;16:551-60.

75. Colla ARS, Rosa JM, Cunha MP, Rodrigues ALS. Anxiolytic-like effects of ursolic acid in mice. Eur J Pharmacol. 2015;758:171-6. 
76. Garau A, Mart MA, Sala J, Balada F. Age effects on the social interaction test in early adulthood male rats. Depress Anxiety. 2000;12:226-31.

77. Savage S, Kehr J, Olson L, Mattsson A. Impaired social interaction and enhanced sensitivity to phencyclidine-induced deficits in novel object recognition in rats with cortical cholinergic denervation. Neuroscience. 2011;195:60-9.

78. Gigliucci V, Leonzino M, Busnelli M, Luchetti A, Palladino VS, D'Amato FR, et al. Region specific up-regulation of oxytocin receptors in the opioid Oprm1 -/- mouse model of autism. Front Pediatr. 2014;2:91.

79. Ventura R, Coccurello R, Andolina D, Latagliata EC, Zanettini C, Lampis V, et al. Postnatal aversive experience impairs sensitivity to natural rewards and increases susceptibility to negative events in adult life. Cereb Cortex 2013;23:1606-17.

80. Strekalova T, Markova N, Shevtsova E, Zubareva O, Bakhmet A, Steinbusch $\mathrm{HM}$, et al. Individual differences in behavioural despair predict brain GSK3beta expression in mice: the power of a modified swim test. Neural Plast. 2016:2016:5098591.

81. Hybels CF, Blazer DG, Pieper CF. Toward a threshold for subthreshold depression: an analysis of correlates of depression by severity of symptoms using data from an elderly community sample. Gerontologist. 2001;41:357-65.

82. Kessler RC, Angermeyer M, Anthony JC, DE Graaf R, Demyttenaere K, Gasquet I, et al. Lifetime prevalence and age-of-onset distributions of mental disorders in the World Health Organization's World Mental Health Survey Initiative. World Psychiatry. 2007;6:168-76.

83. León LA, Cardenas FP. Contribution of the dopaminergic system to the effect of chronic fluoxetine in the rat forced swim test. Psychol Neurosci. 2008;1:81-6.

84. Katsimpardi L, Lledo PM. Regulation of neurogenesis in the adult and aging brain. Curr Opin Neurobiol. 2018;53:131-8

85. Saraulli D, Costanzi M, Mastrorilli V, Farioli-Vecchioli S. The long run: neuroprotective effects of physical exercise on adult neurogenesis from youth to old age. Curr Neuropharmacol. 2017;15:519-33.

86. Hostenbach S, Cambron M, D'haeseleer M, Kooijman R, De Keyser J. Astrocyte loss and astrogliosis in neuroinflammatory disorders. Neurosci Lett. 2014;565:39-41.

87. Cragnolini A, Lampitella G, Virtuoso A, Viscovo I, Panetsos F, Papa M, et al. Regional brain susceptibility to neurodegeneration: what is the role of glial cells? Neural Regen Res. 2020;15:838-42.

88. Jinno S, Kosaka T. Stereological estimation of numerical densities of glutamatergic principal neurons in the mouse hippocampus. Hippocampus. 2010;20:829-40.

89. Jinno S. Decline in adult neurogenesis during aging follows a topographic pattern in the mouse hippocampus. J Comp Neurol. 2011;519:451-66.

90. Franklin KBJ, Paxinos $\mathrm{G}$. The mouse brain in stereotaxic coordinates, compact. 3rd ed. Amsterdam: Elsevier Academic Press; 2008.

91. Mayhew TM, Gundersen HJ. If you assume, you can make an ass out of $u$ and me': a decade of the disector for stereological counting of particles in 3D space. J Anat. 1996;188:1-15.

92. Gundersen HJG, Jensen EBV, Kiêu K, Nielsen J. The efficiency of systematic sampling in stereology - reconsidered. J Microsc. 1999:193:199-211.

93. Jessberger S, Römer B, Babu H, Kempermann G. Seizures induce proliferation and dispersion of doublecortin-positive hippocampal progenitor cells. Exp Neurol. 2005;196:342-51.

94. Kee $\mathrm{N}$, Teixeira $\mathrm{CM}$, Wang $\mathrm{AH}$, Frankland PW. Preferential incorporation of adult-generated granule cells into spatial memory networks in the dentate gyrus. Nat Neurosci. 2007;10:355-62

95. Farioli-Vecchioli S, Saraulli D, Costanzi M, Pacioni S, Cinà I, Aceti M, et al. The timing of differentiation of adult hippocampal neurons is crucial for spatial memory. PLoS Biol. 2008;6:2188-204.

96. Howard CV, Reed M. Unbiased Stereology: Three-dimensional measearument in microscopy. Garland science BIOS Scientific Publishers. Oxford. 1998. p. 53-65.

97. Mouton PR. Principles and practices of unbiased stereology: an introduction for bioscientist: JHU Press; 2002

98. Nobili A, Krashia P, Cordella A, La Barbera L, Dell'Acqua MC, Caruso A, et al. Ambral shapes hippocampal inhibition/excitation balance: role in neurodevelopmental disorders. Mol Neurobiol. 2018;55:7921-40.

99. Delgado M, Camacho AP. Histological study of the gonadal development of Ruditapes decussatus (L.) (Mollusca: Bivalvia) and its relationship with available food. Sci Mar. 2005:69:87-97.

100. Armando A. Fatty acid mass spectrometry protocol. بـىمارىهاى داخلى. 2010.
101. Ferland RJ, Gross RA, Applegate CD. Differences in hippocampal mitotic activity within the dorsal and ventral hippocampus following flurothyl seizures in mice. Neurosci Lett. 2002;332:131-5.

102. Snyder JS, Radik R, Wojtowicz JM, Cameron HA. Anatomical gradients of adult neurogenesis and activity: young neurons in the ventral dentate gyrus are activated by water maze training. Hippocampus. 2009;19:360-70.

103. Piatti VC, Davies-Sala MG, Espósito MS, Mongiat LA, Trinchero MF, Schinder AF. The timing for neuronal maturation in the adult hippocampus is modulated by local network activity. J Neurosci. 2011;31:7715-28.

104. Tanti A, Rainer Q, Minier F, Surget A, Belzung C. Differential environmental regulation of neurogenesis along the septo-temporal axis of the hippocampus. Neuropharmacology. 2012;63:374-84.

105. Dobryakova W, Volobueva MN, Manolova AO, Medvedeva TM, Kvichansky AA, Gulyaeva NV, et al. Cholinergic deficit induced by central administration of $192 \mathrm{lgG}$-saporin is associated with activation of microglia and cell loss in the dorsal hippocampus of rats. Front Neurosci. 2019;13:146.

106. Tang X, Wu D, Yao Y, Gu LH, Chen XC, Ren QG, et al. Dorsal hippocampal changes in $T 2$ relaxation times are associated with early spatial cognitive deficits in 5XFAD mice. Brain Res Bull. 2019;153:150-61.

107. Tournier BB, Tsartsalis S, Rigaud D, Fossey C, Cailly T, Fabis F, et al. TSPO and amyloid deposits in sub-regions of the hippocampus in the 3XTgAD mouse model of Alzheimer's disease. Neurobiol Dis. 2019;121:95-105.

108. Mohajeri MH, Troesch B, Weber P. Inadequate supply of vitamins and DHA in the elderly: implications for brain aging and Alzheimer-type dementia. Nutrition. 2015;31:261-75.

109. Davinelli S, Trichopoulou A, Corbi G, De Vivo I, Scapagnini G. The potential nutrigeroprotective role of Mediterranean diet and its functional components on telomere length dynamics. Ageing Res Rev. 2019:49:1-10.

110. Lever C, Burton S, O'Keefe J. Rearing on hind legs, environmental novelty, and the hippocampal formation. Rev Neurosci. 2006;17:111-33.

111. Hennebelle M, Balasse L, Latour A, Champeil-Potokar G, Denis S, Lavialle M, et al. Influence of omega-3 fatty acid status on the way rats adapt to chronic restraint stress. PLoS One. 2012;7:e42142.

112. Dyall SC, Michael GJ, Michael-Titus AT. Omega-3 fatty acids reverse agerelated decreases in nuclear receptors and increase neurogenesis in old rats. J Neurosci Res. 2010;88:2091-102.

113. Tokuda H, Kontani M, Kawashima H, Kiso Y, Shibata H, Osumi N. Differential effect of arachidonic acid and docosahexaenoic acid on age-related decreases in hippocampal neurogenesis. Neurosci Res. 2014;88:58-66.

114. Nag N, Baxter MG, Berger-Sweeney JE. Efficacy of a murine-p75-saporin immunotoxin for selective lesions of basal forebrain cholinergic neurons in mice. Neurosci Lett. 2009;452:247-51.

115. Pizzo DP, Thal $\sqcup$, Winkler J. Mnemonic deficits in animals depend upon the degree of cholinergic deficit and task complexity. Exp Neurol. 2002;177:292-305.

116. Paban V, Jaffard M, Chambon C, Malafosse M, Alescio-Lautier B. Time course of behavioral changes following basal forebrain cholinergic damage in rats: environmental enrichment as a therapeutic intervention. Neuroscience. 2005;132:13-32.

117. Winters BD, Bussey TJ. Removal of cholinergic input to perirhinal cortex disrupts object recognition but not spatial working memory in the rat. Eur J Neurosci. 2005;21:2263-70

118. Matchynski JJ, Lowrance SA, Pappas C, Rossignol J, Puckett N, Sandstrom $M$, et al. Combinatorial treatment of tart cherry extract and essential fatty acids reduces cognitive impairments and inflammation in the mu-p75 saporin-induced mouse model of Alzheimer's disease. J Med Food. 2013;16:288-95.

119. Shoji H, Takao K, Hattori S, Miyakawa T. Age-related changes in behavior in C57BL/6J mice from young adulthood to middle age. Mol Brain. 2016:9:11

120. Dautan D, Bay HH, Bolam JP, Gerdjikov TV, Mena-Segovia J. Extrinsic sources of cholinergic innervation of the striatal complex: a whole-brain mapping analysis. Front Neuroanat. 2016;10:1.

121. Nizari S, Carare RO, Romero IA, Hawkes CA. 3D reconstruction of the neurovascular unit reveals differential loss of cholinergic innervation in the cortex and hippocampus of the adult mouse brain. Front Aging Neurosci. 2019;11:172

122. De Kloet ER, Molendijk ML. Coping with the forced swim stressor: towards understanding an adaptive mechanism. Neural Plast. 2016;2016:6503162.

123. van der Staay FJ, Bouger P, Lehmann O, Lazarus C, Cosquer B, Koenig J, et al. Long-term effects of immunotoxic cholinergic lesions in the septum 
on acquisition of the cone-field task and noncognitive measures in rats. Hippocampus. 2006;16:1061-79.

124. Dobryakova Y, Kasianov A, Zaichenko MI, Stepanichev MY, Chesnokova EA, Kolosov PM, et al. Intracerebroventricular administration of 192lgG-saporin alters expression of microglia-associated genes in the dorsal but not ventral hippocampus. Front Mol Neurosci. 2017;10:429.

125. Sastre M, Klockgether T, Heneka MT. Contribution of inflammatory processes to Alzheimer's disease: molecular mechanisms. Int J Dev Neurosci. 2006;24: $167-76$

126. Ho NF, Han S, Dawe GS. Effect of voluntary running on adult hippocampal neurogenesis in cholinergic lesioned mice. BMC Neurosci. 2009;10:57.

127. Vinot N, Jouin M, Lhomme-Duchadeuil A, Guesnet P, Alessandri JM, Aujard $F$, et al. Omega-3 fatty acids from fish oil lower anxiety, improve cognitive functions and reduce spontaneous locomotor activity in a non-human primate. PLoS One. 2011;6:e20491.

128. Grundy T, Toben C, Jaehne EJ, Corrigan F, Baune BT. Long-term omega-3 supplementation modulates behavior, hippocampal fatty acid concentration, neuronal progenitor proliferation and central TNF-Ît expression in 7 month old unchallenged mice. Front Cell Neurosci. 2014;8:399.

129. Pusceddu MM, Kelly P, Ariffin N, Cryan JF, Clarke G, Dinan TG. n-3 PUFAs have beneficial effects on anxiety and cognition in female rats: effects of early life stress. Psychoneuroendocrinology. 2015;58:79-90.

130. Samieri C, Maillard P, Crivello F, Proust-Lima C, Peuchant E, Helmer C, et al. Plasma long-chain omega-3 fatty acids and atrophy of the medial temporal lobe. Neurology. 2012;79:642-50.

131. Tan ZS, Harris WS, Beiser AS, Au R, Himali JJ, Debette S, et al. Red blood cell omega-3 fatty acid levels and markers of accelerated brain aging Neurology. 2012;78:658-64

132. Titova OE, Sjögren $P$, Brooks SJ, Kullberg J, Ax E, Kilander L, et al. Dietary intake of eicosapentaenoic and docosahexaenoic acids is linked to gray matter volume and cognitive function in elderly. Age (Dordr). 2013;35:1495-505.

133. Pottala JV, Yaffe K, Robinson JG, Espeland MA, Wallace R, Harris WS. Higher RBC EPA 1 DHA corresponds with larger total brain and hippocampal volumes: WHIMS-MRI Study. Neurology. 2014;82:435-42.

134. Dash PK, Mach SA, Moore AN. Enhanced neurogenesis in the rodent following traumatic brain injury. J Neurosci Res. 2001;63:313-9.

135. Sakurai A, Tamvacakis AN, Katz PS. Recruitment of polysynaptic connections underlies functional recovery of a neural circuit after lesion. Eneuro. 2016;3: ENEURO.0056-16.2016.

136. Liu J, Solway K, Messing RO, Sharp FR. Increased neurogenesis in the dentate gyrus after transient global ischemia in gerbils. J Neurosci. 1998;18: 7768-78.

137. Jin K, Minami M, Lan JQ, Mao XO, Batteur S, Simon RP, et al. Neurogenesis in dentate subgranular zone and rostral subventricular zone after focal cerebral ischemia in the rat. Proc Natl Acad Sci U S A. 2001;98:4710-5.

138. Jin K, Galvan V, Xie L, Mao XO, Gorostiza OF, Bredesen DE, et al. Enhanced neurogenesis in Alzheimer's disease transgenic (PDGF-APP Sw,Ind) mice. Proc Natl Acad Sci U S A 2004;101:13363-13367.

139. Jin K, Peel AL, Mao XO, Xie L, Cottrell BA, Henshall DC, et al. Increased hippocampal neurogenesis in Alzheimer's disease. Proc Natl Acad Sci U S A. 2004;101:343-7.

140. Lazic SE. Modeling hippocampal neurogenesis across the lifespan in seven species. Neurobiol Aging. 2012;33:1664-71.

141. Kempermann G, Gast D, Gage FH. Neuroplasticity in old age: sustained fivefold induction of hippocampal neurogenesis by long-term environmental enrichment. Ann Neurol. 2002;52:135-43.

142. Kaneko N, Okano H, Sawamoto K. Role of the cholinergic system in regulating survival of newborn neurons in the adult mouse dentate gyrus and olfactory bulb. Genes Cells. 2006;11:1145-59.

143. Mohapel P, Leanza G, Kokaia M, Lindvall O. Forebrain acetylcholine regulates adult hippocampal neurogenesis and learning. Neurobiol Aging. 2005;26: 939-46.

144. Campbell NR, Fernandes CC, Halff AW, Berg DK. Endogenous signaling through a7-containing nicotinic receptors promotes maturation and integration of adult-born neurons in the hippocampus. J Neurosci. 2010;30: 8734-44.

145. Barceló-Coblijn G, Högyes E, Kitajka K, Puskás LG, Zvara Á, Hackler L, et al. Modification by docosahexaenoic acid of age-induced alterations in gene expression and molecular composition of rat brain phospholipids. Proc Natl Acad Sci U S A. 2003:100:11321-6.
146. Willis LM, Shukitt-Hale B, Joseph JA. Dietary polyunsaturated fatty acids improve cholinergic transmission in the aged brain. Genes Nutr. 2009;4:309-14.

147. Deng W, Aimone JB, Gage FH. New neurons and new memories: how does adult hippocampal neurogenesis affect learning and memory? Nat Rev Neurosci. 2010;11:339-50.

148. Diniz LP, Matias ICP, Garcia MN, Gomes FCA. Astrocytic control of neural circuit formation: highlights on TGF-beta signaling. Neurochem Int. 2014;78: $18-27$.

149. Chung WS, Allen NJ, Eroglu C. Astrocytes control synapse formation, function, and elimination. Cold Spring Harb Perspect Biol. 2015;7:a020370.

150. Chung WS, Verghese PB, Chakraborty C, Joung J, Hyman BT, Ulrich JD, et al. Novel allele-dependent role for APOE in controlling the rate of synapse pruning by astrocytes. Proc Natl Acad Sci U S A. 2016;113:10186-91.

151. Liddelow SA, Guttenplan KA, Clarke LE, Bennett FC, Bohlen CJ, Schirmer L, et al. Neurotoxic reactive astrocytes are induced by activated microglia. Nature. 2017;541:481-7.

152. Nichols NR, Day JR, Laping NJ, Johnson SA, Finch CE. GFAP mRNA increases with age in rat and human brain. Neurobiol Aging. 1993;14:421-9.

153. Wakabayashi K, Hayashi S, Yoshimoto M, Kudo H, Takahashi H. NACP/asynuclein-positive filamentous inclusions in astrocytes and oligodendrocytes of Parkinson's disease brains. Acta Neuropathol. 2000;99:14-20.

154. Braak H, Sastre M, Del Tredici K. Development of alpha-synuclein immunoreactive astrocytes in the forebrain parallels stages of intraneuronal pathology in sporadic Parkinson's disease. Acta Neuropathol. 2007;114:231-41.

155. Palmer AL, Ousman SS. Astrocytes and aging. Front Aging Neurosci. 2018; 10:337

156. Heneka MT, Kummer MP, Latz E. Innate immune activation in neurodegenerative disease. Nat Rev Immunol. 2014;14:463-77.

157. Thomas J, Thomas CJ, Radcliffe J, Itsiopoulos C. Omega-3 fatty acids in early prevention of inflammatory neurodegenerative disease: a focus on Alzheimer's disease. Biomed Res Int. 2015;2015:172801.

158. Solbrig MV, Fan Y, Hermanowicz N, Morgese MG, Giuffrida A. A synthetic cannabinoid agonist promotes oligodendrogliogenesis during viral encephalitis in rats. Exp Neurol. 2010;226:231-41.

159. Matias I, Morgado J, Gomes FCA. Astrocyte heterogeneity: impact to brain aging and disease. Front Aging Neurosci. 2019;11:59.

160. McGrattan AM, McGuinness B, McKinley MC, Kee F, Passmore P, Woodside $\mathrm{J}$, et al. Diet and inflammation in cognitive ageing and Alzheimer's disease. Curr Nutr Rep. 2019;8:53-65.

161. Bazinet RP, Layé S. Polyunsaturated fatty acids and their metabolites in brain function and disease. Nat Rev Neurosci. 2014;15:771-85.

162. Devassy JG, Leng S, Gabbs M, Monirujjaman M, Aukema HM. Omega-3 polyunsaturated fatty acids and oxylipins in neuroinflammation and management of Alzheimer disease. Adv Nutr. 2016;7:905-16.

163. Morgese MG, Schiavone S, Mhillaj E, Bove M, Tucci P, Trabace L. N-3 PUFA diet enrichment prevents amyloid beta-induced depressive-like phenotype. Pharmacol Res. 2018;129:526-34.

164. Morgese MG, Schiavone S, Maffione AB, Tucci P, Trabace L. Depressive-like phenotype evoked by lifelong nutritional omega-3 deficiency in female rats: crosstalk among kynurenine, Toll-like receptors and amyloid beta oligomers. Brain Behav Immun. 2020;87:444-54.

\section{Publisher's Note}

Springer Nature remains neutral with regard to jurisdictional claims in published maps and institutional affiliations.

Ready to submit your research? Choose BMC and benefit from:

- fast, convenient online submission

- thorough peer review by experienced researchers in your field

- rapid publication on acceptance

- support for research data, including large and complex data types

- gold Open Access which fosters wider collaboration and increased citations

- maximum visibility for your research: over $100 \mathrm{M}$ website views per year

At $\mathrm{BMC}$, research is always in progress.

Learn more biomedcentral.com/submissions 